Universidade de São Paulo

Faculdade de Medicina de Ribeirão Preto

\title{
2021
}

Efeito adicional da educação em neurociência da dor sobre

a intensidade da dor e incapacidade em pacientes com dor

lombar crônica: ensaio clínico aleatorizado
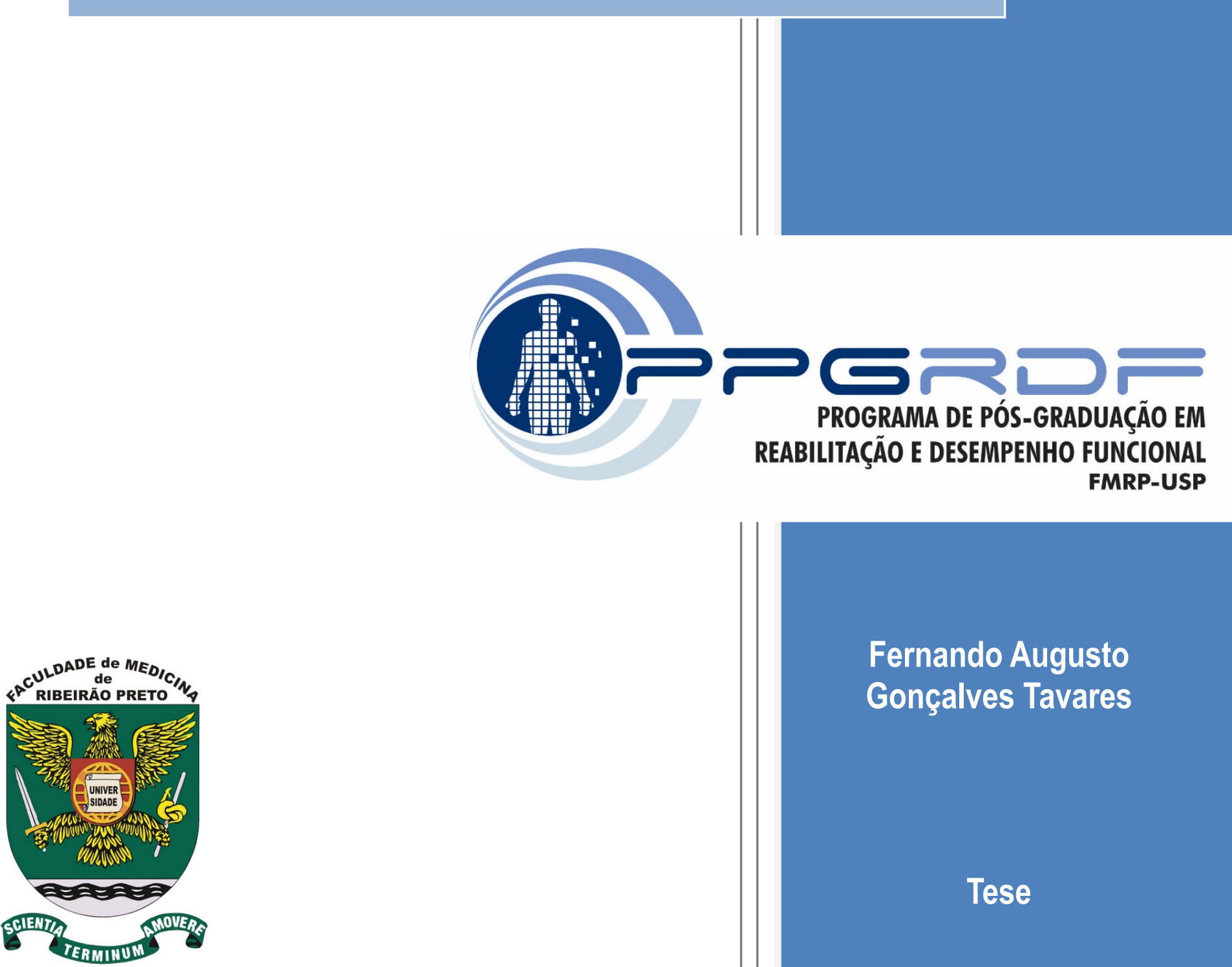

Fernando Augusto

Gonçalves Tavares 
UNIVERSIDADE DE SÃO PAULO

FACULDADE DE MEDICINA DE RIBEIRÃO PRETO

Departamento de Neurociências e Ciências do Comportamento

FERNANDO AUGUSTO GONÇALVES TAVARES

\section{Efeito adicional da educação em neurociência da dor sobre a intensidade da dor e incapacidade em pacientes com dor lombar crônica: ensaio clínico aleatorizado}

Tese apresentada à Faculdade de Medicina de Ribeirão Preto da Universidade de São Paulo junto ao Departamento de Ciências da Saúde, para obtenção do título de mestre em Reabilitação e Desempenho Funcional. A versão original encontra-se disponível na secretaria do programa de pós graduação em Reabilitação e Desempenho Funcional.

Área de concentração: Fisioterapia

Orientadora: Profa. Dra. Thais Cristina Chaves

Ribeirão Preto 
Autorizo a reprodução e divulgação total ou parcial deste trabalho, por qualquer meio convencional ou eletrônico, para fins de estudo e pesquisa, desde que citada a fonte.

\section{Catalogação da Publicação}

Faculdade de Medicina de Ribeirão Preto da Universidade de São Paulo

Tavares, Fernando Augusto Gonçalves

Efeito adicional da educação em neurociência da dor sobre a intensidade da dor e incapacidade em pacientes com dor lombar crônica: ensaio clínico aleatorizado. Ribeirão Preto, 2021.

$$
\text { p.90: } 11.5 ; 30 \mathrm{~cm}
$$

Tese de Mestrado, apresentada à Faculdade de Medicina de Ribeirão Preto/USP Programa de Pós Graduação Reabilitação e Desempenho Funcional.

Área de concentração: Fisioterapia.

Orientador: Chaves, Thais Cristina.

1. Dor Lombar Crônica. 2. Terapia Manual. 3. Educação em Neurociência da Dor. 4. Intensidade da Dor. 5. Incapacidade. 
UNIVERSIDADE DE SÃO PAULO

FACULDADE DE MEDICINA DE RIBEIRÃO PRETO

Departamento de Neurociências e Ciências do Comportamento

FERNANDO AUGUSTO GONÇALVES TAVARES

Efeito adicional da educação em neurociência da dor sobre a intensidade da dor e incapacidade em pacientes com dor lombar crônica: ensaio clínico aleatorizado 


\section{FOLHA DE APROVAÇÃO}

Fernando Augusto Gonçalves Tavares

Efeito adicional da educação em neurociência da dor sobre a intensidade da dor e incapacidade em pacientes com dor lombar crônica: ensaio clínico aleatorizado.

Tese apresentada à Faculdade de Medicina de Ribeirão Preto da Universidade de São Paulo junto ao Departamento de Ciências da Saúde, para obtenção do título de doutora em Reabilitação e Desempenho Funcional

Área de concentração: Fisioterapia

Aprovado em:

\section{Banca Examinadora}

Profa Dra. Thais Cristina Chaves

Instituição: Departamento de Fisioterapia - Univerdidade Federal de São Carlos UFSCar

Assinatura:

Prof Dra

Instituição:

Assinatura:

Profa Dra

Instituição:

Assinatura:

Profa Dra

Instituição:

Assinatura: 
Dedicado ao Senhor... Meu Deus Pai, Deus Filho e

Deus Espírito Santo. A Ti, toda honra! 


\section{Agradecimentos}

É fato que nada podemos fazer sozinhos. Minha gratidão eterna pelo dom da vida, graça e favor ao meu Senhor que até aqui me ajudou e sustentou em momentos que eu nem sabia que poderia suportar.

Gratidão ao amor, suporte e carinho, esforço contínuo, confiança na minha capacidade. Vocês nunca duvidaram!! Muito, mas muito obrigado Mãe e esposa.

Aos familiares e amigos que muitas vezes tem mais clareza sobre minha capacidade do que eu mesmo.

Aos meus alunos que tornaram possível esse imenso desafio, em meio a tantos, se dedicaram a um projeto como se fosse deles. Em especial, João, Witor, Gabi e Letícia.

Aos colegas do laboratório que me ajudaram em minhas dificuldades e sempre estiveram dispostos e disponíveis.

Minha Professora, que talvez nem saiba o quanto teve de influência sobre o curso da minha vida profissional. Obrigado por me aceitar da forma como eu sou... Ou fui.

Ao orgulho de realizar um sonho e estar nesta Instituição!

O presente trabalho foi realizado com apoio da Coordenação de perfeiçoamento de Pessoal de Nível Superior - Brasil (CAPES) - Código de Financiamento 001”. 
"Pois, quando sou fraco é que sou forte. 2 Coríntios 12:10

Theodore Roosevelt 
TAVARES, F.A.G. Efeito adicional da educação em neurociência da dor sobre a intensidade da dor e incapacidade em pacientes com dor lombar crônica: ensaio clínico aleatorizado. 2021. 90f. Tese (Mestrado) - Faculdade de Medicina de Ribeirão Preto FMRP-USP, Universidade de São Paulo, Ribeirão Preto.

\section{Resumo}

Introdução: Dor lombar pode ser considerada uma das principais causas de incapacidade musculoesquelética com comprometimento de estruturas adjacentes e articulações secundárias levando a compensações biomecânicas e sobrecarga. Cerca de 10 a 40\% dos indivíduos que apresentam dor lombar desenvolvem a forma crônica. Evidências sugerem que a Terapia Manual (TM) tem apresentado resultados efetivos no tratamento da dor lombar crônica (DLC). Influências biopsicossociais são reconhecidas como fatores contribuintes no quadro de DLC incorporando crenças sobre a dor na associação com incapacidade e alteração nos padrões de movimento, reforçando a relação entre desempenho motor e fatores psicossociais. A educação em neurociências sobre a dor (END) consiste em um conjunto de intervenções cognitivas cujo objetivo principal é resignificar crenças sobre a dor. Não há na literatura estudos publicados verificando o efeito adicional de um programa de END a um protocolo de TM.

Objetivo: O objetivo do presente estudo foi avaliar o efeito adicional da END na TM na intensidade da dor e incapacidade relacionada a dor lombar imediatamente e no acompanhamento de um mês em pacientes com DLC.

Tipo do estudo: Ensaio Clínico Aleatorizado

Hipótese: A hipótese deste estudo foi que os pacientes submetidos a END e a TM apresentariam melhores resultados para intensidade da dor e incapacidade relacionada à lombar do que pacientes submetidos apenas a TM, bem como, nos níveis de medoevitação, autoeficácia e percepção global de melhora quando comparados ao grupo TM isolada.

Participantes: Cento e quatro pacientes com DLC de ambos os sexos com idade entre 18 e 55 anos.

Intervenções: Educação em Neurociência da Dor + Terapia Manual (TM + END) comparado com TM isolado.

Principais Medidas de Resultado: Os desfechos primários do estudo foram intensidade da dor e incapacidade. Os desfechos secundários foram crenças sobre medo-evitação, efeito global percebido e autoeficácia para manejo da dor. Os resultados foram obtidos imediatamente após o tratamento e em três acompanhamentos (30 dias, 90 dias e 180 dias). Análises de modelos lineares mistos foram usadas para investigar diferenças entre os grupos.

Resultados: Não foram observadas diferenças significativas entre os grupos para a intensidade da dor imediatamente após o tratamento, diferença média estimada (MD) (F $=0.72 \mathrm{p}=0.57, \mathrm{MD}=0.15, \mathrm{IC} 95 \%-0,84$ a 1.14) e incapacidade imediatamente após tratamento estimado $(\mathrm{F}=0.51 \mathrm{p}=0.72, \mathrm{MD}=-1.65, \mathrm{CI} 95 \%-3,25$ a 6,56). Nenhuma diferença entre os grupos foi observada também nos acompanhamentos para intensidade da dor e incapacidade. No entanto, um aumento significativo intragrupo para intensidade da dor foi observado apenas para o grupo submetido a TM isolada seguimento de 180 dias em comparação com a avaliação pós-tratamento imediato.

Conclusões: Não foi encontrado nenhum efeito adicional do END na TM para a intensidade da dor e incapacidade em pacientes com DLC. Os resultados deste estudo sugerem que a adição de END à TM não trouxe nenhum efeito adicional para a intensidade da dor e incapacidade em pacientes com DLC em curto prazo. No entanto, encontramos um maior efeito estatisticamente e clinicamente relevante a longo prazo para a combinação de estratégias (TM + END) quando comparada à TM isolada. 
TAVARES, F.A.G. Efeito adicional da educação em neurociência da dor sobre a intensidade da dor e incapacidade em pacientes com dor lombar crônica: ensaio clínico aleatorizado. 2021. 90f. Tese (Mestrado) - Faculdade de Medicina de Ribeirão Preto FMRP-USP, Universidade de São Paulo, Ribeirão Preto.

Número de registro do ensaio clínico: NCT03356886.

Palavras-chave: Dor Lombar Crônica, Terapia Manual, Educação em Neurociência da Dor, Intensidade da Dor, Incapacidade. 
TAVARES, F.A.G. Additional effect of pain neuroscience education on pain and disability for patients with chronic low back pain: a randomized clinical trial. 2021. 90f. Thesis (Master's degree) - Ribeirão Preto Medical School, University of São Paulo, Ribeirão Preto.

\section{Abstract}

Background: Low back pain can be considered one of the main causes of musculoskeletal incapacity with involvement of adjacent structures and secondary joints, leading to biomechanical compensation and overload. About 10 to $40 \%$ of people with low back pain develop the chronic form. Evidence suggests that Spinal Manipulative Therapy (SMT) has shown effective results in the treatment of chronic low back pain (CLBP). Biopsychosocial influences are recognized as contributing factors in the CLBP framework, incorporating beliefs about pain in association with disability and changes in movement patterns, reinforcing the relationship between motor performance and psychosocial factors. Pain Neuroscience Education (PNE) consists of a set of cognitive interventions whose main objective is to change the patient's concept of the referred symptom and there are no published studies in the literature verifying the additional effect of a PNE to SMT protocol.

Objective: The objective of the current study was to evaluate the additional effect of PNE to SMT on pain intensity and low back related disability immediately and at one-month follow-up in patients with CLBP.

Design: Randomized Clinical Trial

Hypothesis: The hypothesis of this study was that patients undergoing PNE and SMT would have better results for pain intensity and disability related to the lower back than patients undergoing only SMT, as well as for fear-avoidance levels, self-efficacy and global perception of improvement when compared to the isolated MT group.

Participants: One hundred and four patients with CLBP from both sexes aged between 18 to 55 years.

Interventions: Pain Neuroscience Education + Spinal Manipulative Therapy (SMT) compared to SMT alone.

Main Outcome Measures: The primary outcome measures were pain intensity and disability. The secondary outcomes were fear-avoidance beliefs, global perceived Effect and pain self-efficacy. The outcomes were obtained immediately post treatment, and in three follow-ups (30-day, 90-day and 180-day). Linear mixed model analyses were used to investigate between-group differences.

Results: No significant between group differences was observed for pain intensity immediate after treatment estimated mean difference $(\mathrm{MD})(\mathrm{F}=0.72 \mathrm{p}=0.57, \mathrm{MD}=0.15$, $\mathrm{CI} 95 \%-0.84$ to 1.14$)$ and disability score immediate after estimated $(\mathrm{F}=0.51 \mathrm{p}=0.72$, $\mathrm{MD}=-1.65, \mathrm{CI} 95 \%-3.25$ to 6.56 ). No between-group difference was observed also at the follow-ups for pain intensity and disability. However, a significant within-group increase in pain intensity was observed just for the group submitted to SMT alone at the 180-dayfollow-up compared to the post treatment assessment.

Conclusions: It was not found no additional effect of PNE to SMT for pain intensity and disability in patients with CLBP. The results of this trial suggest the addition of PNE to SMT did not bring any additional effect for pain intensity and disability in patients with 
TAVARES, F.A.G. Additional effect of pain neuroscience education on pain and disability for patients with chronic low back pain: a randomized clinical trial. 2021. 90f. Thesis (Master's degree) - Ribeirão Preto Medical School, University of São Paulo, Ribeirão Preto.

CLBP in the short term. However, we found a greater long-term statistically and clinically relevant effect for the combination of strategies (PNE + SMT) when compared to the spinal manipulative therapy alone.

\section{Clinical Trial Registration Number: NCT03356886.}

Keywords: Chronic Low Back Pain, Spinal Manipulative Therapy, Pain Neuroscience Education, Pain intensity, Disability. 


\section{LISTA DE TABELAS}

Tabela 1. Descrição [média e desvio padrão (DP)] dos dados de linha de base dos

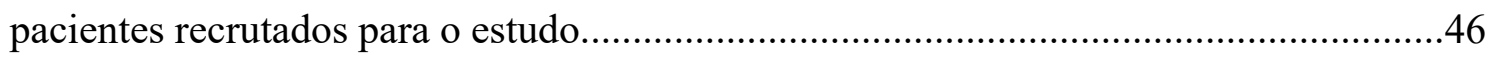

Tabela 2. Comparações entre grupos para os desfechos primários. TM (Terapia Manual) vs $\mathrm{TM}+$ END (Terapia Manual + Educação em

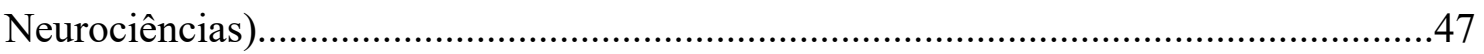

Tabela 3. Comparações entre grupos para os desfechos secundários. TM (Terapia Manual) vs TM + END (Terapia Manual + Educação em

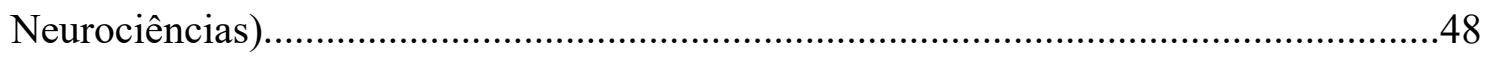




\section{LISTA DE FIGURAS}

Figura 1. Modelo abrangente dos mecanismos de terapia manual...............................21

Figura 2. Fluxograma ilustrando as etapas do estudo.................................................33

Figura 3. Manipulação global de baixa amplitude e alta velocidade na região torácica...40

Figura 4. Mobilização central póstero-anterior na região lombar. . .40

Figura 5. Slide referente ao item 5 "A saída da dor pode ser deflagrada pela memória, não apenas pela nocicepção" utilizada na sessão 1 do programa de

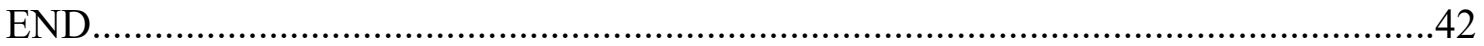




\section{LISTA DE SIGLAS}

CM Centímetro

CONSORT Consolidated Standards of Reporting Trials

DLC Dor lombar crônica

DP Desvio Padrão

END Educação em Neurociência da Dor

NPRS Escala Numérica de Dor

FABQ Fear Avoidance Beliefs Questionnaire | Questionário de Crenças,

Medo Evitação

FMRP Faculdade de Medicina de Ribeirão Preto

GPE Global Perceived Effect | Escala de Percepção do Efeito Global

HADS Hospital Anxiety and Depression Scale | Escala de Depressão e

Ansiedade Hospitalar

IASP Associação Internacional para o Estudo da Dor

IC Intervalo de confiança

IMC Índice de massa corpórea

IMMPACT Initiative on Methods, Measurement and Pain Assessment in

Clinical Trials

Kg Quilogramas

M $\quad$ Metro

MCID Mínima Diferença Clinicamente Importante

MMSE Mini-Mental State Examination

NICE National Institute for Health and Care Excellence

NIR Núcleo Integrado de Reabilitação 
Lombar

PCS

PSES

sobre a Dor

RPC

RPCm

SBST

SPSS

TM
Pain Catastrophyzing Scale | Escala de Catastrofização da Dor

Pain Self-Efficacy Questionnaire | Questionário de Auto Eficácia

Regra de predição clínica

Regra de predição clínica modificada

StarT Back Screening Tool

Statistical Package for Social Science

Terapia Manipultativa 


\section{SUMÁRIO}

1. INTRODUÇÃO ............................................................................................................................ 18

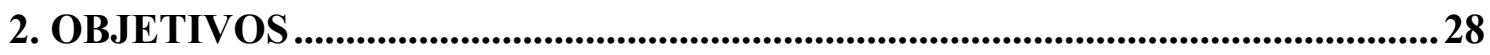

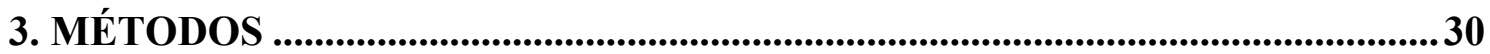

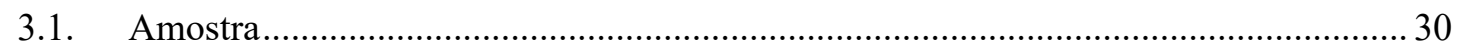

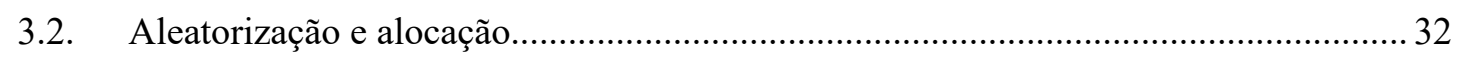

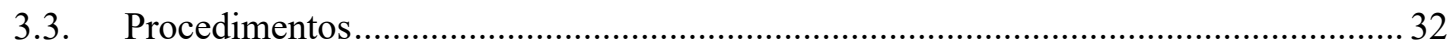

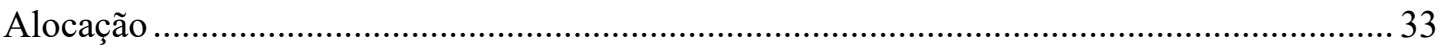

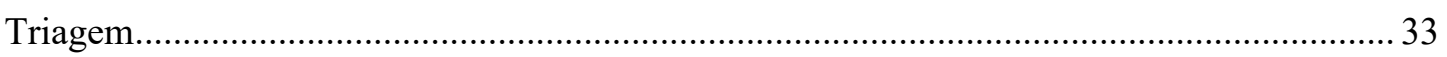

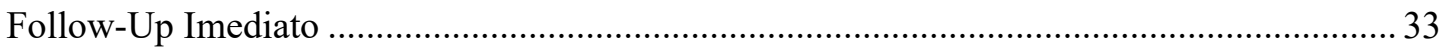

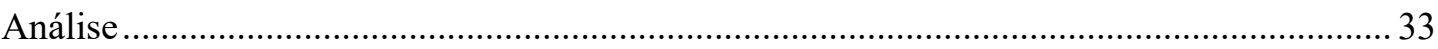

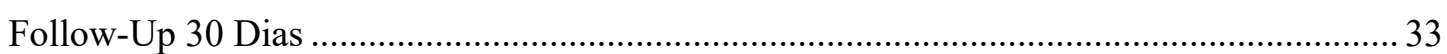

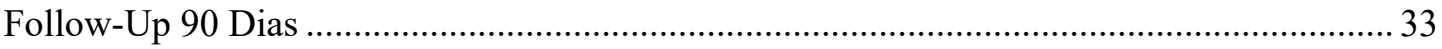

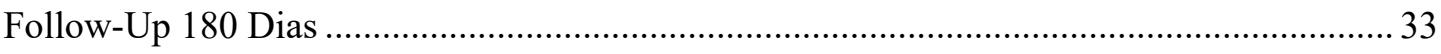

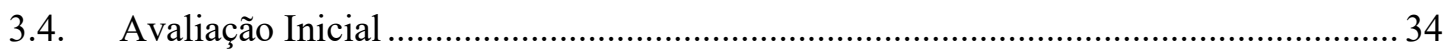

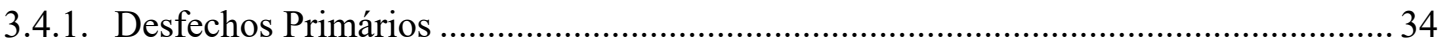

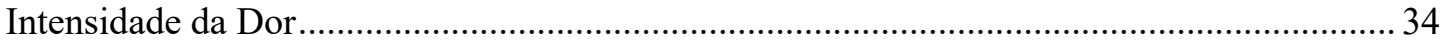

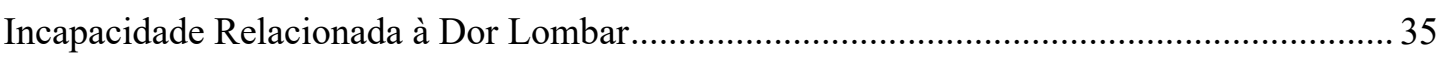

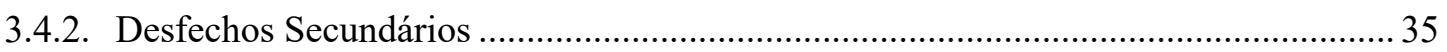

Avaliações dos Participantes de Melhora Global e Satisfação com o Tratamento ................... 35

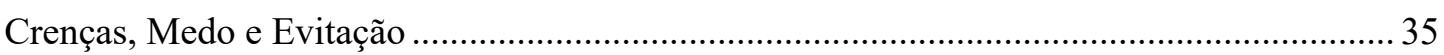

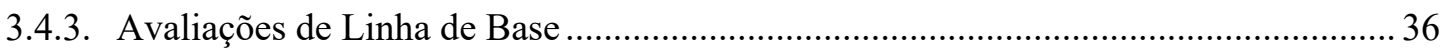

3.4.3.1. Mini-Mental State Examination (MMSE) .......................................................... 36

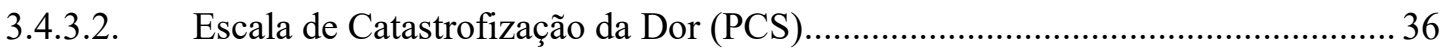

3.4.3.3. Questionário de Auto Eficácia sobre a Dor (PSES) ............................................ 37

3.4.3.4. Escala de Ansiedade e Depressão Hospitalar (HADS).......................................... 37

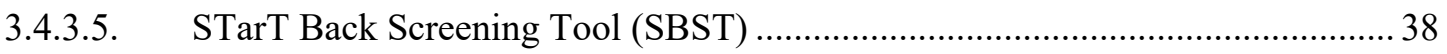

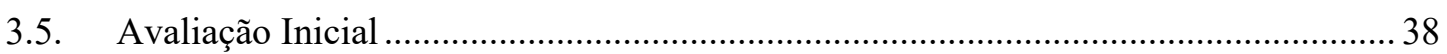

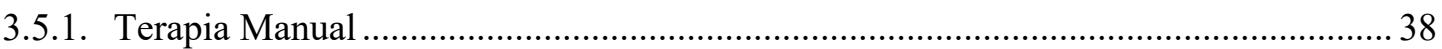

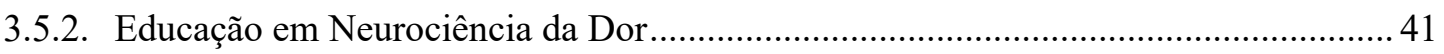

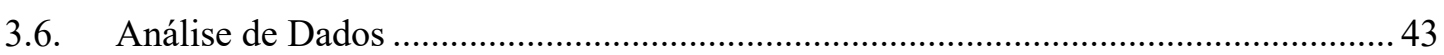

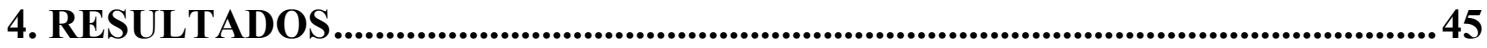

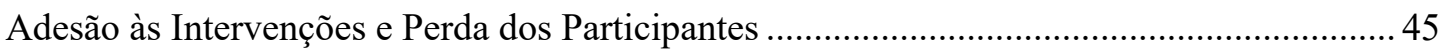

Características de Linha de Base dos Participantes.................................................................. 45

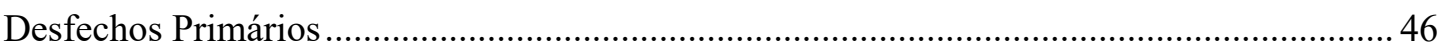

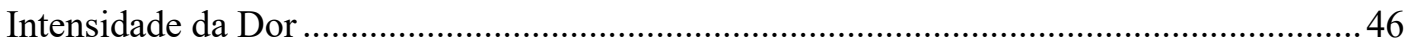

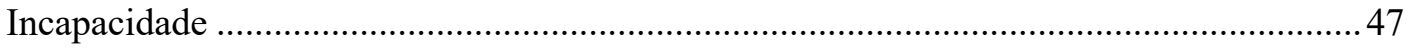


5. DISCUSSÃO 54

6. CONCLUSÃO .61

7. REFERÊNCIAS .63

APÊNDICE A - Termo de Consentimento Livre e Esclarecido ................................. 74

ANEXO A - Documento de aprovação do projeto ..................................................76

ANEXO A - Mini Exame do Estado Mental ............................................................. 77

ANEXO B - Escala Numérica de Dor .........................................................................78

ANEXO C - Índice de Incapacidade Lombar Oswestry (ODI)................................. 79

ANEXO D - Fear Avoidance Beliefs Questionnaire (FABQ-Brasil)........................81

ANEXO E - Escala de Autoeficácia Sobre Dor (PESE) ..........................................82

ANEXO F - Escala de Percepção Global da Efeito (GPE) ........................................ 84

ANEXO G - StarT Back Screening Tool (SBST Brasil) ........................................85

ANEXO H - Escala de Pensamentos Catastróficos Sobre a Dor (PCS) .................... 86

ANEXO I - Escala de Ansiedade e Depressão Hospitalar (HADS).........................87 


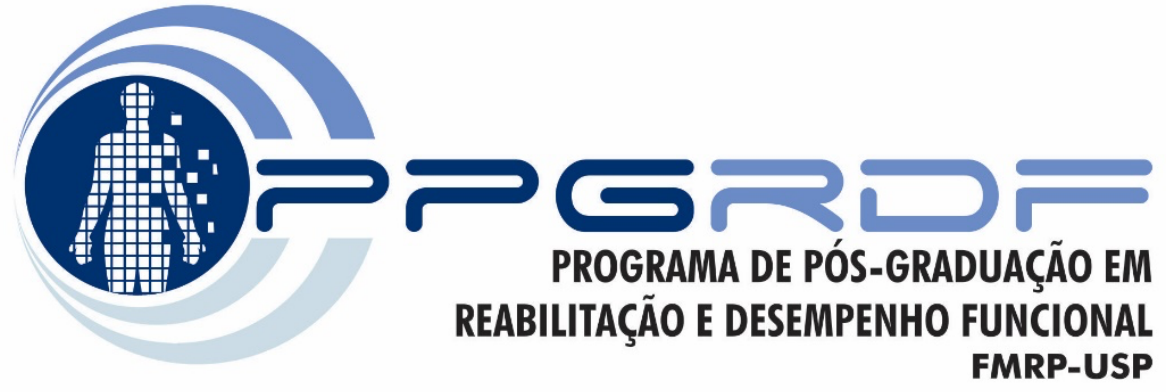

INTRODUÇÃO

“O primeiro dever da inteligência é desconfiar dela mesma."

Albert Einstein 


\section{INTRODUÇÃO}

O conceito de dor crônica foi revisado e definido pela Associação Internacional para o Estudo da Dor (IASP) em 2020 como uma experiência sensorial e emocional desagradável associada a, ou semelhante àquela associada $\mathrm{a}$, dano real ou potencial do tecido (Raja et al 2020; de Santana et al, 2020). Em termos gerais, é responsável por 30\% das 10 principais condições que motivam atendimentos de saúde (Murray et al, 2013) e no Global Burden of Diseases (2019), dor lombar foi a quarta causa de anos de vida perdidos por incapacidade na faixa etária entre 25-49 anos.

Assim sendo, dor lombar é uma das condições musculoesqueléticas mais incapacitantes do mundo (Hoy et al, 2014) com características multifatoriais que podem afetar as atividades funcionais e, consequentemente, gerar custos econômicos crescentes de forma direta ou indireta (Mafi et al, 2013).

A prevalência mundial é de aproximadamente $12 \%$ da população global sofrendo de dor lombar em algum momento da vida (Hoy et al, 2012) com 33\% dos pacientes (IC95\% 28-38) apresentando recorrência nos 12 meses seguintes ao primeiro episódio (Booth et al, 2017). Esse quadro coloca pacientes com dor lombar entre as cinco principais causas de procura pela atenção primária gerando aumento contínuo de intervenções que visam alívio e controle da dor (Deyo et al, 2009). Geralmente essas abordagens são cirúrgicas, medicamentosas e não medicamentosas (Rajaee et al, 2012).

No entanto, é possível que abordagens passivas isoladas se mostrem limitadas no controle pleno da dor e na restauração da capacidade de função dos indíviduos (Koes et al, 2006). E esse fato pode ser compreendido porque, mesmo que a queixa possa envolver estruturas adjacentes à coluna vertebral e levar à compensação e sobrecarga biomecânica (Chou et al, 2007), a maioria das dores lombares são classificadas como inespecíficas 


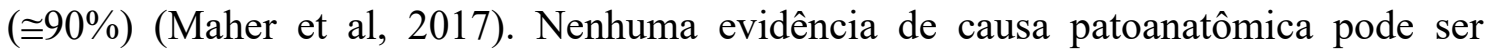
encontrada através dos exames de imagem disponíveis (Maher et al, 2017).

As diretrizes do National Institute for Health and Care Excellence (NICE, 2021) recomendam programas de terapias ativas (exercícios) e abordagens psicológicas (terapia de aceitação e compromisso e terapia cognitivo-comportamental) como possíveis abordagens para o tratamento de condições crônicas de dor. Atualmente, exercícios estão entre as estratégias mais recomendadas por sua natureza ativa de autocuidado e por todos os benefícios adicionais alcançados como consequência de sua prática (Cohen et al, 2021). E mesmo que existam recomendações de guidelines que sugiram a associação de terapias físicas e educação (Wong et al, 2017), até o momento, nenhum tratamento foi aceito como padrão-ouro para dor lombar.

Evidências de muito baixa ou baixa qualidade sugerem que Terapia Manual (TM) não é superior a outros tratamentos na redução de medo e evitação, cinesiofobia e catastrofização da dor em curto prazo em pacientes em condições musculoesqueléticas crônicas (Kamonseki et al, 2021). Para alívio da dor e melhora da função em curto, médio e longo prazo em pacientes com dor lombar crônica, evidências de qualidade moderada e pequeno efeito sugerem que a $(\mathrm{TM})$ mostrou resultados efetivos semelhantes às terapias recomendadas (Rubinstein et al, 2019).

Mas TM pode ser definida como uma variedade de técnicas manuais de natureza complexa que podem ser categorizadas de acordo com a estrutura onde são aplicadas e quanto ao efeito desejado (Bialosky et al, 2009). Mobilização e manipulação são exemplos de técnicas manuais aplicadas nas articulações quando efeito estimado é a diminuição do espasmo muscular, melhora da amplitudade de movimento e consequente diminuição da intensidade da dor (Bialosky et al, 2009). 
Coulter et al. (1996) definem mobilização como a aplicação criteriosa de força manual de baixa velocidade e amplitude variável dentro do limite articular passivo (1996). Conceitualmente, manipulação pode ser definida como um impulso manual dinâmico de alta velocidade e baixa amplitude além do limite articular passivo (Bronfort et al, 2004; Coulter et al, 1996).

Bialosky et al. (2009) propuseram um modelo inicial (Figura 1) na tentativa de compreender e explicar os mecanismos inibitórios da dor na TM. Esse modelo sugere que o estímulo mecânico da intervenção resulta em efeitos biomecânicos e neurofisiológicos, particularmente na interação entre ambos, sugerindo respostas neurofisiológicas dependentes de dose e de parâmetros biomecânicos específicos (Bialosky et al, 2009; Coronado et al, 2012; Millan et al, 2012). Esse modelo reconhece e aceita a influência de mecanismos inespecíficos, como expectativa e placebo, e seu papel nos desfechos clínicos resultantes da TM.

A utilização clínica clássica da TM é tradicionalmente compreendida por mecanismos de ação periférica de resposta direta ao estímulo manual. Por exemplo, pelo aumento da mobilidade de uma articulação rígida ou da modulação da hiperexcitabilidade do motoneurônio $\gamma$ em um espamo muscular (Henderson et al, 2012; Clark et al, 2012). No entanto, evidências sugerem que até mesmo os efeitos considerados puramente mecânicos são respostas neurofisiológicas resultantes de diminuição da hipoalgesia mecânica e atividade muscular normalizada (Lascurain-Aguirrebeña et al, 2016).

Outros modelos têm sido desenhados aceitando e considerando mecanismos centrais modulatórios da dor em resposta à TM (Bialosky et al, 2018) e os avanços da tecnologia de neuroimagem tem favorecido a compreensão das mudanças na função cortical em resposta ao estímulo manual (Ogura et al, 2011). Existem relatos de hipoalgesia associada à redução da atividade cortical pós impulso manipulativo torácico 
em indivíduos saudáveis (Sparks et al, 2013) e atividade neural do giro pós-central, partes do córtex insular e cingulado, além do cerebelo após pressão póstero-anterior dos processos espinhosos das vértebras lombares em indivíduos saudáveis (Meier et al, 2013).

Esse modelo (Bialosky et al, 2018) considera ainda fatores contextuais tanto para os pacientes quanto para os profissionais de saúde provedores das técnicas manipulativas que podem ser considerados na compreensão dos mecanismos de ação da TM.

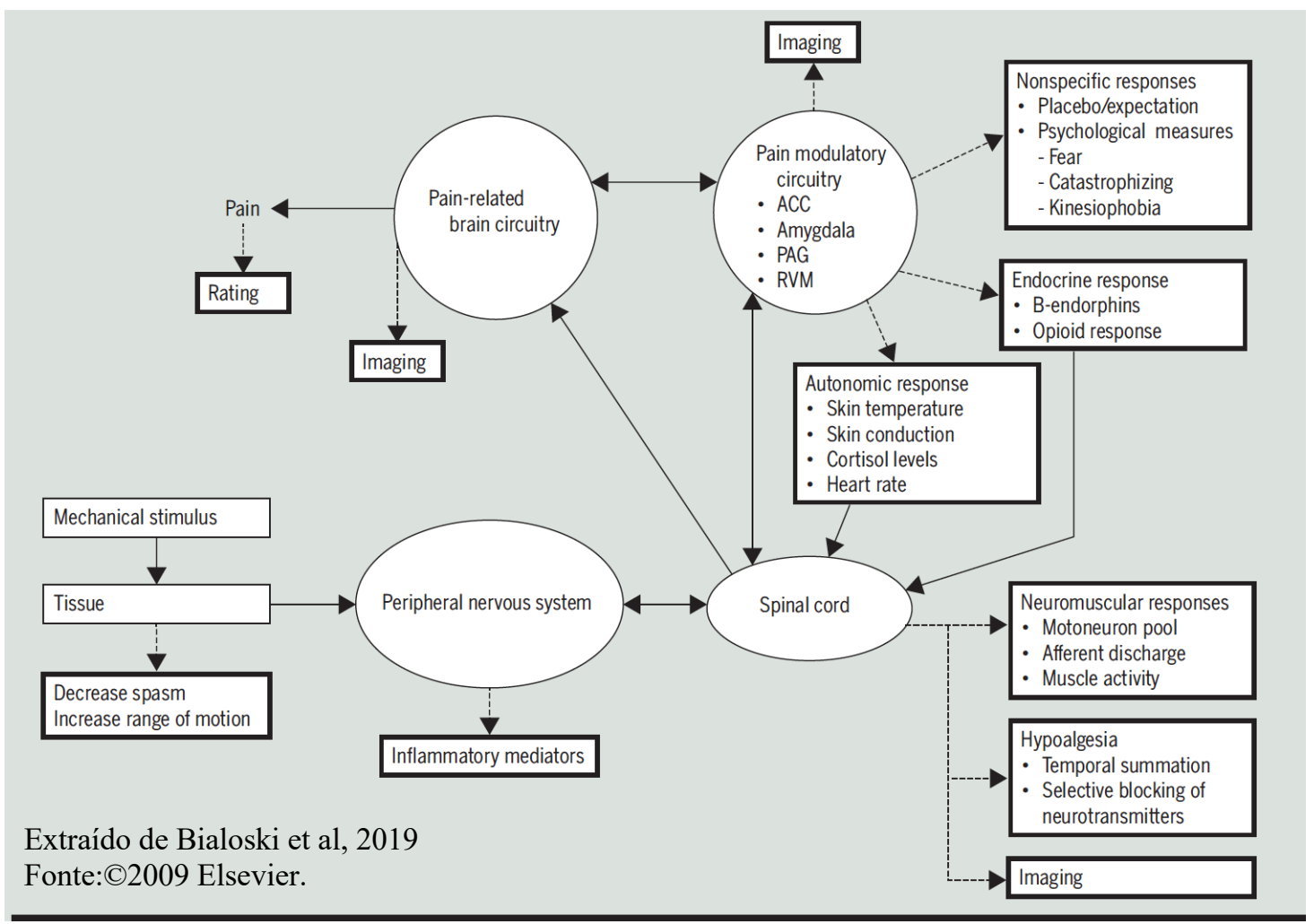

Figura 1. Modelo abrangente dos mecanismos de terapia manual. O modelo sugere que um estímulo mecânico transitório ao tecido produz uma cadeia de efeitos neurofisiológicos. Setas sólidas denotam um efeito de mediação direto. Setas quebradas denotam um relacionamento associativo, que pode incluir uma associação entre um construto e sua medida. As caixas em negrito indicam a medição de uma construção. Abreviaturas: ACC, córtex cingulado anterior; PAG, cinza periaquedutal; RVM, medula rostral ventromedial

Por exemplo, mesmo que não haja diferença significativa entre manipulação ou mobilização (Cook et al, 2013) em regiões específicas ou inespecíficas (de Oliveira et al, 2013) para intensidade da dor e incapacidade em pacientes com dor lombar crônica (DLC), preferências e expectativas do profissional de saúde provedor das técnicas 
manipulativas podem ser considerados como preditores dos resultados da TM (Cook et al, 2013; Bialosky et al, 2018).

Concomitantemente, apesar das cumulativas evidências de que DLC está associada a uma complexa interação de fatores físicos, psicológicos, estilo de vida e neurofisiológicos (O'Keeffe et al, 2015), com muitos desses fatores sendo potencialmente modificáveis, as intervenções mais atuais ainda não estão focadas em múltiplos fatores da experiência de dor de um indivíduo. Portanto, não é de surpreender que tratamentos como TM, exercícios ou medicamentos, embora melhorem resultados específicos, não sejam superiores entre si e tenham um impacto limitado na dor a longo prazo (Hayden et al, 2005; Wang et al. al, 2012; Chaparro et al, 2013; Menke et al, 2014).

Influências biopsicossociais são reconhecidas como fatores contribuintes no quadro de DLC incorporando crenças sobre a dor na associação com incapacidade e alteração nos padrões de movimento, reforçando a relação entre desempenho motor e fatores psicossociais (Moseley et al., 2002). Se consideramos o papel nativo da dor como função protetora, comportamentos prejudiciais podem ser evitados e a integridade fisiológica preservada (D’Mello, 2008). Mas os fatores contextuais podem desempenhar um papel de interferência na modulação dos estímulos aferentes antes de atingir os centros espinais superiores (Gatchel et al, 2007). Diferentes regiões cerebrais interpretam os estímulos recebidos da periferia e geram intensidades de respostas que podem estar condicionadas à ameaça, consciência, memórias e afetividade facilitando ou inibindo as vias descendentes modulatórias da dor (Gatchel et al, 2007; Moseley et al, 2015).

As diretrizes de Prática Clínica recomendam o uso de um modelo biopsicossocial para avaliação e tratamento da dor lombar, tendo em vista as associações entre fatores biológicos, psicológicos e sociais no desenvolvimento de dor persistente e incapacidade (NICE et al, 2016; Lin et al, 2019). Diante desse cenário, há um movimento em direção 
ao emprego de tratamentos multimodais com o objetivo de abordar fatores biológicos e psicossociais no tratamento da dor crônica (Booth et al, 2017). Uma revisão sistemática endossou os efeitos superiores de intervenções biopsicossociais à fisioterapia isolada, como exercício ou fisioterapia (Kamper et al., 2014). Uma dessas abordagens psicossociais é a educação da dor.

Intervenções educativas em dor compreendem a transferência de informações de forma didática e organizada com objetivo de alterar crenças inadequadas e reduzir comportamentos adaptativos (Clarke, et al, 2011). Abordagens biomédicas tradicionais enfatizam o conceito de dor como resultado de dano tecidual, aumentando o senso de restringir atividade funcional com o intuito de "proteger a região acometida". Durante a educação em neurociêncida da dor (END) são abordados os aspectos psicossociais da dor relacionados com o funcionamento do sistema nervoso e como as crenças limitantes podem favorecer a manutenção da dor e incapacidade (Moseley e Butler, 2015; Wertli et al, 2014). Além disso, parte importante da END é resignificar conceitos tais como: "toda dor significa que há lesão nos tecidos", "quando sinto dor estou machucando mais ainda os tecidos", "exercício físico não é algo seguro para alguém que tenha dor" e "a dor persistente significa que algo grave está acontecendo no corpo".

END pode ser realizada de variadas formas, seja através de em sessões individuais ou em grupo, em uma ou mais sessões, de modo presencial ou online. Metáforas podem ser empregadas para contextualizar de forma simplificada e que faça sentido para quem recebe sobre os conceitos de como a dor funciona (Louw et al, 2019; Moseley e Butler, 2015).

Efeitos favoráveis da END na intensidade da dor e incapacidade foram demonstrados quando combinada com tratamentos ativos (Bodes Pardo et al, 2018). Uma revisão sistemática demonstrou evidência moderada que a combinação de END e 
intervenções adicionais de fisioterapia resultou em respostas mais favoráveis à intensidade e incapacidade da dor em curto prazo mesmo que com um tamanho de efeito pequeno (Watson et al, 2019) do que quando comparada com END isolada. Por outro lado, existe um consenso na literatura sobre a importância de realizar novos estudos sobre esse tema (Clarke et al, 2011; Geneen et al, 2015).

Além disso, embora um estudo anterior tenha associado os efeitos da END e da TM, sua proposta foi avaliar o efeito das abordagens educacionais (END vs. orientações para auto-manejo) associadas ao emprego de TM aplicadas em uma única sessão com cinco minutos de duração (Louw et al, 2017). Existe ainda um estudo publicado no qual a TM associada a uma intervenção psicológica foram aplicados em pacientes com DLC (Petrozzi et al, 2019). No entanto, a intervenção psicológica não é uma abordagem END.

Dessa forma, para preencher essa lacuna na literatura, estudos que investiguem o efeito adicional da END em um protocolo TM podem ser valiosos.

A maior parte dos ensaios clínicos contempla intervenções considerando os pacientes com DLC como um grupo homogêneo, enquanto alguns estudos (Cleland et al, 2007) sugerem que as respostas aos tratamentos podem ser potencializadas quando os pacientes são classificados em subgrupos considerando-se as especificidades de seu quadro clínico. As RPCs surgiram na tentativa de identificar pacientes que melhor respondem a tipos específicos de tratamento (Borkan et al, 1998) a partir de uma combinação de características (Baldwin et al, 2007; Schmidt et al, 2008). Elementos variados dessas características clínicas são combinados para prever prognósticos prováveis em resposta a tratamentos precisos (McGinn et al, 2000).

Para o desenvolvimento de uma RPC são necessárias diversas etapas como: 1) derivação (análise de um conjunto de dados para estabelecer uma regra com poder preditivo), 2) validação restrita (avaliação da regra em ambiente clínico e população 
semelhante), 3) validação ampla (avaliação da regra em vários cenários clínicos) e 4) análise de impacto (determinando se a regra muda o comportamento dos clínicos, melhora os resultados do paciente ou reduz os custos). E antes que essas RPCs sejam utilizadas em práticas clínicas ou rotinas de pesquisa é sugerido sejam validadas (McGinn et al, 2000; Laupacis et al, 1997).

Uma revisão sistemática conduzida com o objetivo de avaliar criticamente e considerar a utilidade clínica das RPCs conclui com pouca evidência que RPCs podem ser utilizadas como preditores de efeitos de tratamentos de pacientes em condições musculoesqueléticas e devem ser utilizadas com cautela (Stanton et al, 2010). Esse mesmo estudo citou uma única RPC validada e considerada para aplicação clínica (Flynn et al, 2002).

Na RPC desenvolvida por Flynn et al. (2002) foram consideradas cinco variáveis: 1) duração dos sintomas $<16$ dias; 2) rotação interna de quadril com $>35^{\circ}, 3$ ) hipomobilidade lombar, 4) ausência de sintomas distais no joelho e 5) pontuação FABQ Work $<19$. Pacientes com DLC tendem a ter uma maior amplitude na rotação externa em comparação com a rotação interna de quadril e o aumento da rotação interna estava associado ao sucesso da manipulação (Mellin, 1988). Manipulações, mesmo que com características inespecíficas, são indicadas em hipomobilidade articular e podem ter efeitos em segmentos adjacentes mesmo que não sintomáticos (Delitto et al, 1995). Manipulações são contraindicadas em radiculopatias e por isso pacientes com sinais de compressão de raiz nervosa foram excluídos (Bigos et al, 1994). Finalmente, pacientes com escores elevados sobre crenças de medo-evitação não responderam bem a manipulação e provavelmente requerem outras abordagens de tratamento (Klenerman et al, 1995; Flynn et al, 2002). 
As RPCs permitem que indivíduos com quadros heterogêneos podem ser direcionados para subgrupos de tratamento através de um sistema de classificação estabelecido por regras preditivas adequadas capazes de detectar possíveis aumentos da efetividade de resposta a um tratamento específico (Flynn et al, 2002). Um ensaio clínico que avaliou os efeitos imediatos na intensidade da dor e incapacidade da TM específica vs TM inespecífica em pacientes com DLC (de Oliveira et al, 2013) sugerem que os mecanismos de ação da TM poderiam ser melhor analisados em pacientes que fossem mais responsivos a esses procedimentos através de uma RPC (Bialosky et al, 2018). 


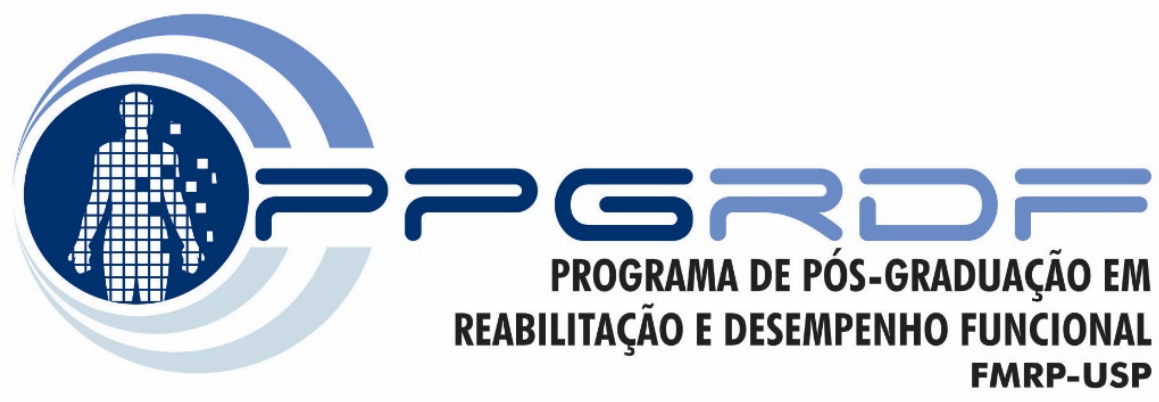

OBJETIVOS

“A beleza das coisas existe no espírito de quem as

contempla."

David Hume 
\begin{tabular}{c|c} 
Objetivos & 28
\end{tabular}

\section{OBJETIVOS}

O principal objetivo do estudo foi avaliar o efeito adicional da END associado a TM na intensidade da dor e na incapacidade relacionada à dor lombar imediatamente $\mathrm{e}$ após um mês de acompanhamento em pacientes com DLC.

Como desfechos secundários, foram verificados os efeitos dos protocolos sobre crenças sobre medo-evitação, autoeficácia e percepção global de melhora. A hipótese deste estudo foi que os pacientes submetidos a END e a TM apresentariam melhores resultados para intensidade da dor e incapacidade relacionada à lombar do que pacientes submetidos apenas a TM, bem como, nos níveis de medo-evitação, autoeficácia e percepção global de melhora quando comparados ao grupo TM isolada. 


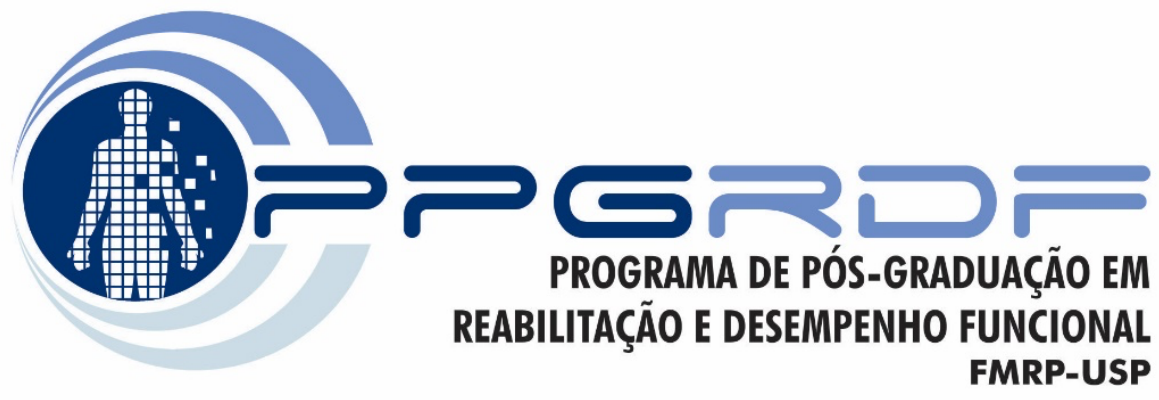

\section{MÉTODOS}

"Não importa a sua velocidade, desde que você siga em frente."

Confúcio 


\section{MÉTODOS}

Este estudo foi um ensaio clínico aleatorizado seguindo às recomendações do Consolidated Standards of Reporting Trials - CONSORT (Moher et al, 2012).

\subsection{Amostra}

Considerando um power de $90 \%, \alpha=0,05$, foi necessário um tamanho de amostra de 80 participantes para detectar uma diferença entre grupos de pelo menos 3 unidades $(\mathrm{DP}=4,5)($ Ostelo et al, 2008) com um tamanho de efeito de 0,67 na escala numérica de dor. No entanto, para o índice de incapacidade relacionada à dor lombar (ODI), 90 participantes foram necessários para detectar uma diferença de 10 unidades ( $\mathrm{DP}=16$ ) (Ostelo et al, 2008) com um tamanho de efeito $=0,62$. Considerando uma perda amostral de 15\% $(\mathrm{n}=90)$, o tamanho da amostra necessário foi de 104 voluntários. Os valores de DP considerados foram os valores máximos de variação absoluta descritos por Ostelo et al. (2008) para calcular a variação mínima significativa. O software usado para executar o cálculo do tamanho da amostra foi o $\mathrm{G} *$ Power 3.0.10 (University of Kiel, Germany).

Foram selecionados indivíduos de ambos os gêneros do serviço de saúde pública de São José do Rio Preto com os seguintes critérios de elegibilidade: i) idade entre 18 e 55 anos, ii) que apresentassem dor lombar crônica, inespecífica, contínua e recorrente com duração de pelo menos três meses e iii) contemplassem pelo menos três dos seguintes critérios: rotação interna do quadril com $>35^{\circ}$; hipomobilidade da coluna 2-lombar; 3- ausência de sintomas distais do joelho e pontuação FABQ Work < 19 (Flynn et al, 2002; Dougherty et al, 2014).

Flynn et al. (2002) propuseram um sistema de classificação de pacientes com dor lombar em subgrupos de tratamento baseados em achados a partir da história clínica e do exame físico. Para o subgrupo de manipulação, foram analisadas onze variáveis potenciais, sendo que apenas cinco 
foram utilizadas para compor a regra de predição clínica: 1- duração dos sintomas $<16$ dias; 2rotação interna de quadril com $>35^{\circ}, 3$ - hipomobilidade lombar, 4- ausência de sintomas distais no joelho e 5- pontuação $F A B Q$ Work $<19$. Segundo o critério, a presença de pelo menos quatro de cinco itens presentes está associada a uma probabilidade de sucesso para TM de 95\%. Além disso, foi relatada uma taxa de $68 \%$ de probabilidade de sucesso para a adesão a pelo menos três itens do critério.

Dougherty et al. (2014) realizaram um estudo em que propuseram a regra de predição clínica modificada (RPCm) para pacientes com DLC. Apenas o item do critério relativo a dor presente por período menor do que 16 dias foi alterado, permitindo a inclusão de pacientes com DLC. A RPCm recomenda que pelo menos três dos quatro critérios precisam ser contemplados.

Foram considerados critérios de exclusão: (1) gestantes; (2) bandeiras vermelhas (neoplasia, fratura da coluna vertebral, osteomielite vertebral, infecção ou síndrome da cauda eqüina, doenças reumáticas, doenças que comprometem a cognição); (3) radiculopatias ativas; (4) pacientes com déficits cognitivos avaliados de acordo com o Mini Exame do Estado Mental com pontuação menor ou igual a 24 pontos ou 22 pontos (baixa escolaridade) (Kochhann et al, 2010) e (5) fisioterapia prévia para dor lombar nos últimos 12 meses ou submetido a qualquer estratégia de educação em dor. Os pacientes foram instruídos a não usar medicamentos para alívio da dor durante o período de intervenção deste estudo e, se qualquer medicamento for usado, os participantes foram incentivados a relatar.

O projeto foi submetido ao Comitê de Ética do Centro Saúde Escola Cuiabá da Faculdade de Medicina de Ribeirão e aprovado com o número (CAAE:69387916.7.0000.5414). . Também foi registrado prospectivamente no ClinicalTrials.gov com a identificação NCT03356886. O estudo foi conduzido em uma sala de atendimento com 1 maca, 1 mesa e 2 cadeiras no Núcleo Integrado de Reabilitação - NIR de São José do Rio Preto. Todos os pacientes concordantes e incluídos nos 
estudos assinaram Termo de Consentimento Livre e Esclarecido (Anexo 02) contendo informações sobre o estudo, liberdade de adesão e desistência, ausência de danos à vida e direito de preservação da identidade, de acordo com o protocolo de Helsinque.

\subsection{Aleatorização e alocação}

Uma vez que o participante tenha aceitado o convite para participar da pesquisa, um mesmo pesquisador realizou a avaliação clínica e determinou a elegibilidade. Após essa avaliação inicial, os participantes foram divididos seguindo procedimentos simples de aleatorização através do uso do software randomizer, em um dos dois grupos de tratamento através do uso de cartões previamente colocados em envelopes opacos e selados. A sequência de alocação foi gerada por um pesquisador não envolvido na avaliação e nas intervenções, e outro assistente de pesquisa atribuiu os participantes às intervenções.

\subsection{Procedimentos}

Os sujeitos recrutados foram aleatorizados em dois grupos de 52 indivíduos: o grupo Terapia Manual foi submetido à TM isolada e o grupo educação sobre neurociências da dor (EN) associado à TM.

Ambos os grupos foram avaliados na linha de base (antes da sessão inicial de tratamento) (Figura 1) por um pesquisador cegado para as intervenções e responderam à versão português brasileiro dos instrumentos Escala Numérica de Dor, Índice de Incapacidade de Oswestry (Owestry Disability Index - ODI), Fear Avoidance Beliefs Questionnaire (FABQ), Questionário de Auto Eficácia sobre a Dor (Pain Self-Efficacy Questionnaire -PSES), Escala de Percepção Global da Efeito (GPE), StarT Back Screening Tool (SBST), Escala de Expectativa de Recuperação, Escala de Catastrofização da Dor (Pain Catastrophyzing Scale - PCS), e Escala de Depressão e Ansiedade Hospitalar (Hospital Anxiety and Depression Scale - HADS) antes do início da sessão 01. 


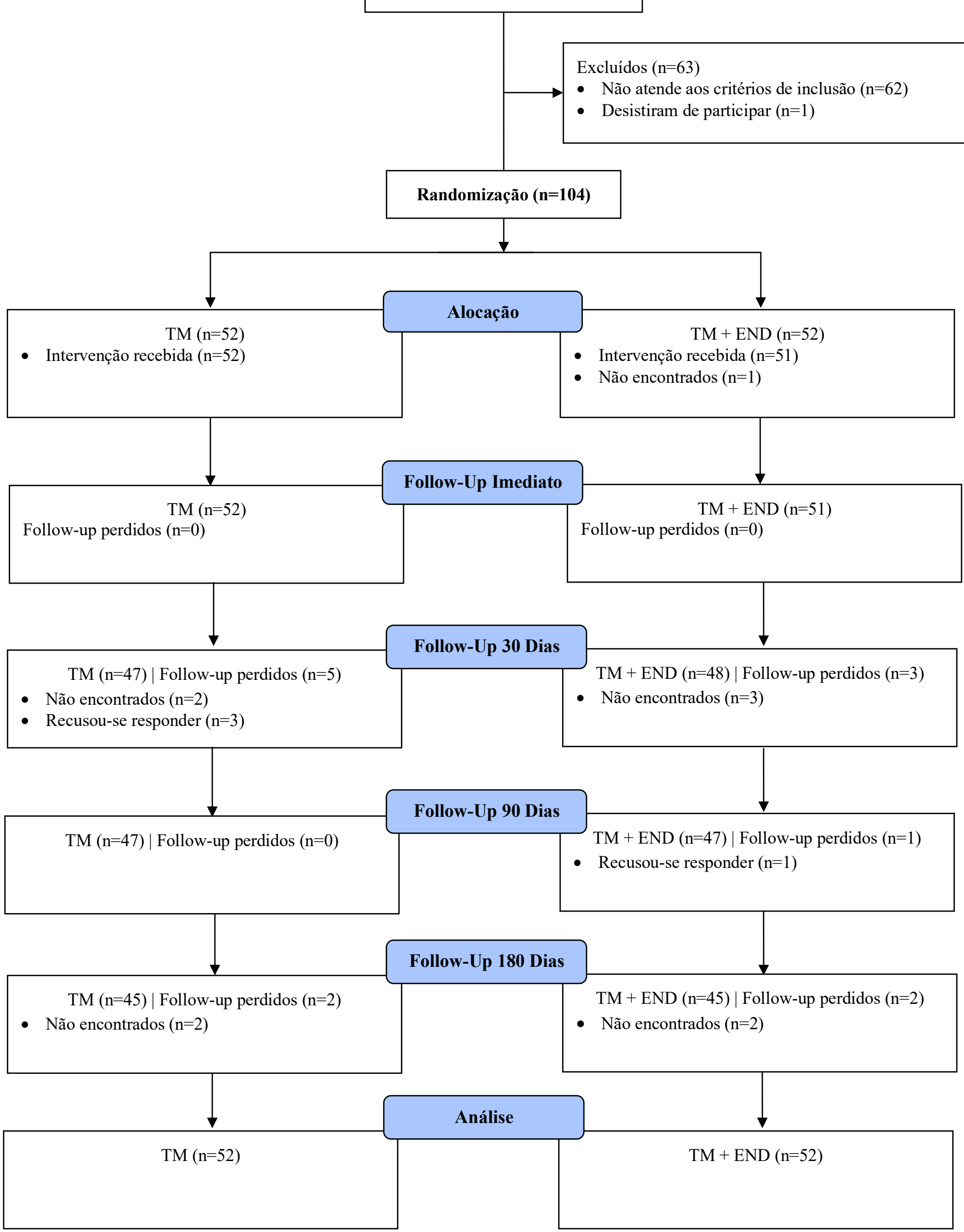

Figura 2. Fluxograma ilustrando as etapas do estudo 
Os desfechos primários considerados neste estudo foram intensidade da dor e incapacidade relacionada à dor lombar. Crenças de medo-evitação, autoeficácia e percepção global de efeito foram considerados como desfechos secundários. Além disso, aspectos relacionados ao prognóstico, catastrofização, ansiedade e a depressão foram controlados na linha de base.

Imediatamente após o término da última sessão, follow up de 30, 90 e 180 dias, foram reaplicados os instrumentos referentes aos desfechos primários: intensidade de dor (END) e incapacidade (ODI) e secundários: O Fear Avoidance Beliefs Questionnaire (FABQ), Questionário de Auto Eficácia sobre a Dor (PSES) e Escala de Percepção Global da Efeito (GPE).

\subsection{Avaliação Inicial}

As avaliações foram realizadas de acordo com as recomendações da Iniciativa sobre Métodos, Medição e Avaliação da Dor em Ensaios Clínicos (IMMPACT) para dor crônica (Dworkin et al, 2005).

\subsubsection{Desfechos Primários}

\section{Intensidade da Dor}

A Escala Numérica de Dor utilizada para avaliar a intensidade da dor neste estudo consiste em uma sequência de números de 0 a 10, em que 0 representa "sem dor" e 10 representa "a pior dor que se possa imaginar" (Costa et al, 2008). A END deve responder à mudança, com uma mínima diferença clinicamente importante (MCID) de 2,4 entre os pacientes com DLC que recebem exercício ou educação (Maughan e Lewis, 2010). 


\section{Incapacidade Relacionada à Dor Lombar}

A versão em português brasileiro do Oswestry Disability Index (ODI) (Vigatto et al, 2007) foi usada para avaliar a incapacidade relacionada à DLC. Este instrumento consiste em 10 itens, cada um dos quais com seis opções de resposta. A pontuação total foi calculada somando todos os pontos, com a maior soma possível sendo 50. Essa soma foi transformada em porcentagem multiplicando-a por dois. Pesquisas anteriores descobriram que o ODI mostrou responsividade à mudança de pacientes com DLC, com MCID de 8 pontos (Maughan e Lewis, 2010).

\subsubsection{Desfechos Secundários}

\section{Avaliações dos Participantes de Melhora Global e Satisfação com o Tratamento}

O efeito global percebido (GPE) usada neste estudo é uma escala de 11 pontos que varia de -5 (“muito pior") a 0 (“sem alteração") a +5 (“completamente recuperado") e os participantes foram convidados: "Comparado a quando esse episódio começou, como você descreveria suas costas hoje em dia?”. Uma pontuação mais alta indica maior percepção de recuperação da condição (Costa et al, 2008) e 2 pontos considerados como MCID (Kamper et al, 2009).

\section{Crenças, Medo e Evitação}

O questionário de crenças, medo e evitação (FABQ) adaptado para o português do Brasil (Abreu et al, 2008) consiste em 16 itens de auto-resposta, classificados em uma escala ordinal de sete pontos de 0 (discordo completamente) a 6 (concordo completamente). A pontuação é obtida para cada subescala separada: uma que aborda os medos e crenças dos indivíduos em relação ao trabalho e outra que aborda seus medos e crenças sobre atividades físicas. Mudanças de 4 pontos 
para FABQ-Physical e 7 pontos para FABQ-Work foram considerados como MCID (Monticone et al, 2020).

Como o conteúdo da END incluiu tópicos sobre prevenção ao medo, o construto foi avaliado. Uma revisão sistemática recente (Wertli et al, 2014) mostrou uma associação entre a crença inicial de evitar o medo e os piores níveis de dor e incapacidade como resultado do tratamento na DLC e mostrou que as intervenções que abordavam medos e crenças eram mais eficazes do que outras baseadas em conceitos biomédicos.

\subsubsection{Avaliações de Linha de Base}

\subsubsection{Mini-Mental State Examination (MMSE)}

O MMSE é uma ferramenta que pode ser usada para avaliar sistematicamente e completamente o estado mental. Utilizamos a versão em português do Brasil da ferramenta (Seabra et al, 1990). É uma medida de 11 perguntas que testa 5 áreas da função cognitiva: orientação, registro, atenção e cálculo, recordação e linguagem. A pontuação máxima é 30. Uma pontuação menor ou igual a 24 pontos ou 22 pontos (baixa escolaridade) é indicativa de comprometimento cognitivo. O MMSE foi utilizado para excluir comprometimento cognitivo.

\subsubsection{Escala de Catastrofização da Dor (PCS)}

A PCS foi traduzida e validada para o português do Brasil por Sehn et al. (2012) foi utilizada. A escala é composta por 13 itens escalonados na escala ordinal de 6 pontos (0-5). A pontuação total é a soma dos itens divididos pelo número de itens respondidos, sendo a pontuação mínima 0 e a máxima 5 para cada item podendo variar entre 0 e 52 pontos. Pontuações finais menores ou maiores 
que 30 pontos, consideram respectivamente 8 (IC 95\% 6-10) e 11 pontos (IC 95\% 8-14) como MCID, variando de acordo com a pontuação total da escala (Monticone et al, 2021).

Escores mais altos indicaram maior presença de pensamentos catastróficos. Uma revisão sistemática constatou que a catastrofização está associada à dor e à incapacidade no acompanhamento em pacientes com DLC (Wertli et al, 2014).

\subsubsection{Questionário de Auto Eficácia sobre a Dor (PSES)}

Os participantes do estudo foram avaliados quanto à autoeficácia relacionada à dor crônica, que pode ser definida como a confiança de um indivíduo em que ele/ela pode produzir com êxito resultados desejáveis relacionados à convivência com dor crônica. A PSES possui 10 itens que são classificados em uma escala ordinal de 7 pontos (variando de 0: "nada confiante" a 6: “completamente confiante”). Para PSES, foi definida uma MCID de 9 pontos (Maughan e Lewis, 2010).

Foi adaptado e validado para o português do Brasil (Sarda et al, 2007). Pesquisas anteriores mostraram um efeito sobre a autoeficácia usando uma intervenção END baseada em metáforas em comparação com uma intervenção usando conceitos cognitivo-comportamentais (Gallagher et al, 2013).

\subsubsection{Escala de Ansiedade e Depressão Hospitalar (HADS)}

A HADS (Pais-Ribeiro et al, 2007) foi empregada para identificar transtornos de ansiedade e depressão. Foi traduzida e validada para o português. A HADS é dividida nas subescalas de ansiedade (HADS-A) e depressão (HADS-D), ambas contendo sete itens intercalados. É composto por sete itens para depressão e sete itens para ansiedade, cada item incluindo quatro opções de resposta que variam de 0 a 3 . Foi descrito um ponto de corte $\geq 8$ com bons valores de sensibilidade e especificidade $(0,70-0,90)$ para sintomas de ansiedade e depressão (Bjelland et al., 2002). 


\subsubsection{STarT Back Screening Tool (SBST)}

O questionário SBST foi traduzido para o português do Brasil (Pilz et al, 2014) e suas medidas psicométricas foram verificadas (Pilz et al, 2014; Pilz et al, 2017). O questionário é composto por 9 itens. Para fins de pontuação e classificação, os respondentes receberam as opções de resposta "concordo" e "discordo" para os 8 primeiros itens, que foram pontuados em 1 e 0 pontos, respectivamente. Para escores totais maiores que 3, a classificação foi baseada na pontuação da subescala psicossocial (itens 5 a 9) da seguinte forma: escores $\leq 3$ correspondiam a risco médio de mau prognóstico e escores $>3$ correspondiam a alto risco de mau prognóstico.

\subsection{Avaliação Inicial}

\subsubsection{Terapia Manual}

Um investigador cegado para as intervenções administradas cumpriu o protocolo de avaliação. Outro pesquisador treinado (fisioterapeuta treinado em TM, 15 anos de experiência clínica) administrou as manobras de TM e um terceiro pesquisador treinado (fisioterapeuta treinado por 12 horas) esteve envolvido na administração da END. O tratamento teve duração de 8 sessões com duração entre 20 e 30 minutos cada.

O protocolo foi composto por: 1) aplicação de uma manipulação global de baixa amplitude e alta velocidade na região torácica superior entre os níveis de T1 e T5 na posição de decúbito dorsal (Figura 2) e 2) técnicas de mobilização central póstero-anterior aplicadas por 30 segundos com média de 30 repetições em cada vértebra lombar, de L5 a L1 (Figura 3), utilizando mobilização articular grau II (pacientes posicionados em decúbito ventral) (Maitland, 2007). As mobilizações articulares são caracterizadas por técnicas específicas de avaliação e intervenção em distúrbios da coluna vertebral e baseiam-se na administração de movimentos passivos e rítmicos. As séries I e II são geralmente empregadas para alívio da dor, enquanto as classes III, IV e V para melhorar a mobilidade articular. 
Nas técnicas manipulativas, os pacientes permaneceram deitados em decúbito dorsal com os membros inferiores estendidos e os antebraços cruzados sobre o tórax. O terapeuta permanenceu em pé ao lado do paciente posicionando os processos espinhosos das vértebras torácicas do paciente no espaço palmar da mão direita do terapeuta entre a região tenar e as articulações interfalangeanas distais do $2^{\circ}$ ao $5^{\circ}$ dedo. Todos os dedos dessa mão permaneceram em flexão.

O tronco do terapeuta foi projetado sobre seu próprio antebraço esquerdo que, por sua vez, estava sobreposto sobre os cotovelos cruzados do paciente em sua linha média. Uma pressão discreta e progressiva foi realizada previamente identificando o limite articular seguindo de um impulso curto e rápido em sentido oblíquo e perpendicular a maca.

Nas mobilizações, os pacientes foram mantidos em decúbito ventral. O terapeuta permanenceu em pé ao lado do paciente posicionando o pisiforme da mão direita relaxada sobre o processo espinhoso das vértebras lombares com uma discreta extensão do punho e desvio radial. O $3^{\circ}, 4^{\circ}$ e $5^{\circ}$ dedos da mão esquerda foram mantidos na face palmar da mão direita e o $1^{\circ}$ e $2^{\circ}$ dedos da mão esquerda na face dorsal da mão direita em posição suave de pinça.

A mão esquerda estabiliza e mantém o posicionamento da mão direita durante a realização das oscilações da manobra. A mão direita se mantém relaxaa para facilitar a palpação e localização precisa das estruturas vertebrais. Ambos cotovelos são flexionados permitindo que a cabeça e o tronco do terapeuta fiquem centralizados sobre a coluna vertebral do paciente, com o esterno alinhado sobre a vértebra mobilizada. Os impulsos são realizados obedecendo o plano articular de deslizamento facetário das vértebras lombares com movimentos oscilatórios fluidos e homogêneos. 


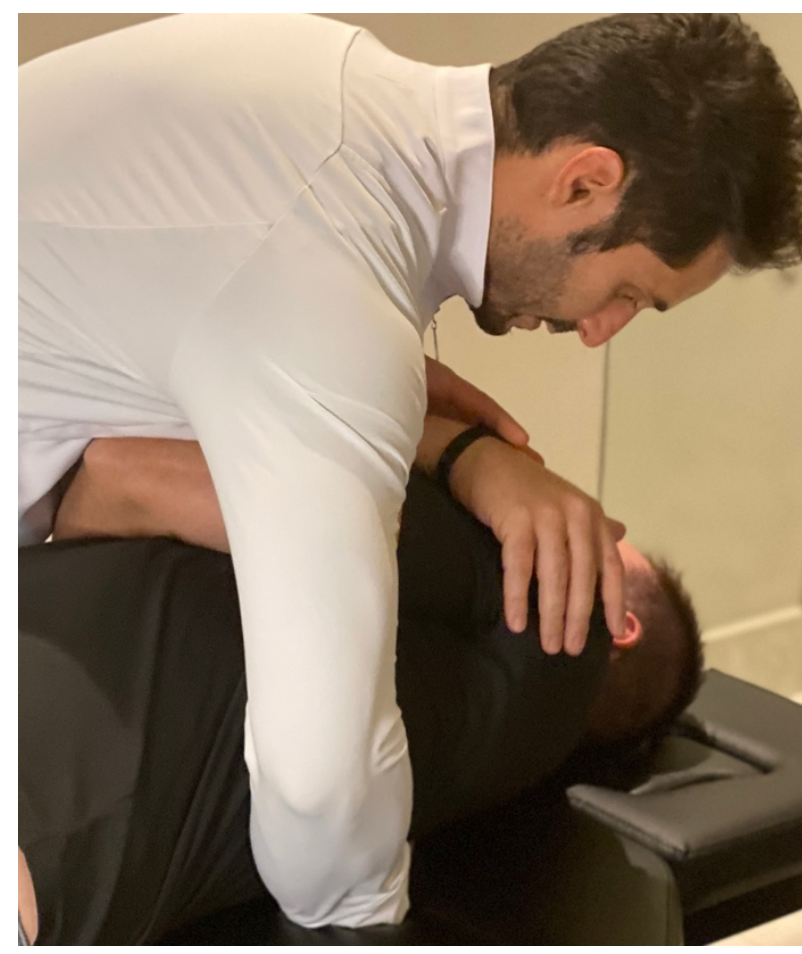

Figura 3. Manipulação global de baixa amplitude e alta velocidade na região torácica.

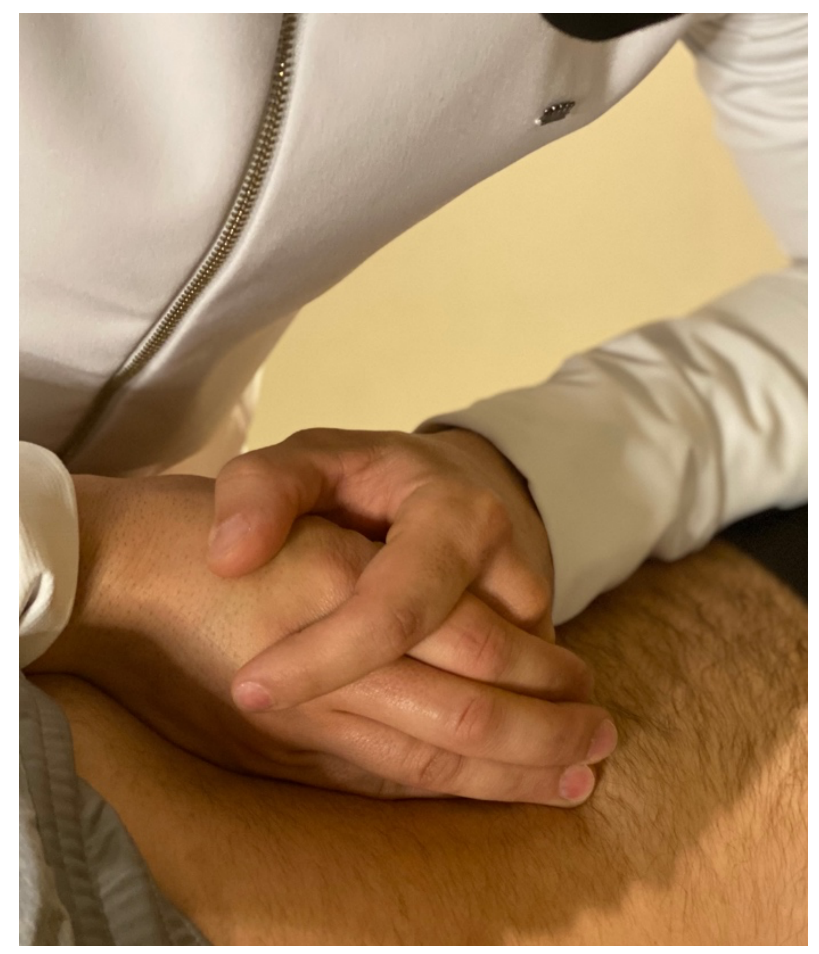

Figura 4. Mobilização central pósteroanterior na região lombar.

Esse protocolo de técnicas combinadas de manipulação e mobilização foi adotado tendo em vista os achados anteriores de uma revisão sistemática (Hidalgo et al, 2014), na qual a combinação de técnicas de mobilização e manipulação mostraram maior evidência (moderada) para intensidade de dor e melhora da função em pacientes com dor lombar crônica quando comparado a cada técnica sozinha (evidência limitada). Técnica de manipulação na coluna torácica e mobilizações na coluna lombar foram utilizadas com o intuito de minimizar que movimentos bruscos aplicados diretamente na região de queixa dolorosa pudessem potencializar efeito nocebo. Além disso, um estudo prévio (de Oliveira et al, 2013) não demonstrou diferenças na intensidade da dor após a manipulação de alta velocidade da coluna lombar em comparação à manipulação não específica (aplicada na região torácica) em pacientes com DLC. Dessa forma, nesse estudo utilizamos um protocolo de TM com manipulações específicas e não específicas. 


\subsubsection{Educação em Neurociência da Dor}

Todos os participantes do grupo END + TM receberam inicialmente um workshop sobre o END, no qual foram discutidos diferentes conceitos de neurociência da dor e reconceitualização da dor em uma apresentação em powerpoint com metáforas e vídeos animados sobre o tema. O programa END foi realizado em 2 sessões de 40 minutos cada. Os tópicos do programa de intervenção foram divididos blocos temáticos, de acordo com os conceitos de Explain Pain (Butler e Moseley, 2013):

1. Contextualização sobre a importância do programa: como a dor causa sofrimento e seu aumento alarmante no mundo

2. Conceitos iniciais em neurociências e dor

3. Como o contexto pode influenciar a percepção da dor - histórias incríveis sobre dor

4. Seres humanos como um complexo multissensorial - as informações sensoriais estão chegando ao cérebro o tempo todo

5. A saída da dor pode ser deflagrada pela memória, não apenas pela nocicepção

6. Nocicepção e o conceito de dor como resposta de proteção

7. Os nociceptores

8. Os conceitos incorretos sobre dor (sistema de dor, receptores de dor, área de dor no cérebro)

9. Conceitos sobre neurofisiologia da dor - sinapses, corno vertebral, neurônios de ordem primária e secundária

10. Tipos de sensibilização

11. Sistema inibitório descendente

12. A mensagem de perigo e o processamento do cérebro

13. O cérebro sensibilizado e sua relação com a dor crônica 
14. A contribuição de outros sistemas para a experiência da dor e vice-versa: endócrino, parassimpático / simpático, imunológico e motor

15. Como ossos, músculos e nervos enviam informações sensoriais o tempo todo

16. Modelo para evitar o medo revisitado

17. Incentivo à mudança

18. Como desenvolver atitudes positivas

19. Conceitos de exposição gradual e atividade gradual

Na sessão 01 do programa END foram abordados os itens entre 1 e 10 e na sessão 02 os itens restantes entre 11 e 19. Após as duas sessões de intervenção de END de 40 minutos, o protocolo de TM foi imediatamente administrado.

Segue abaixo um dos slides utilizados no END que utilizamos e a descrição do conteúdo que foi abordado.

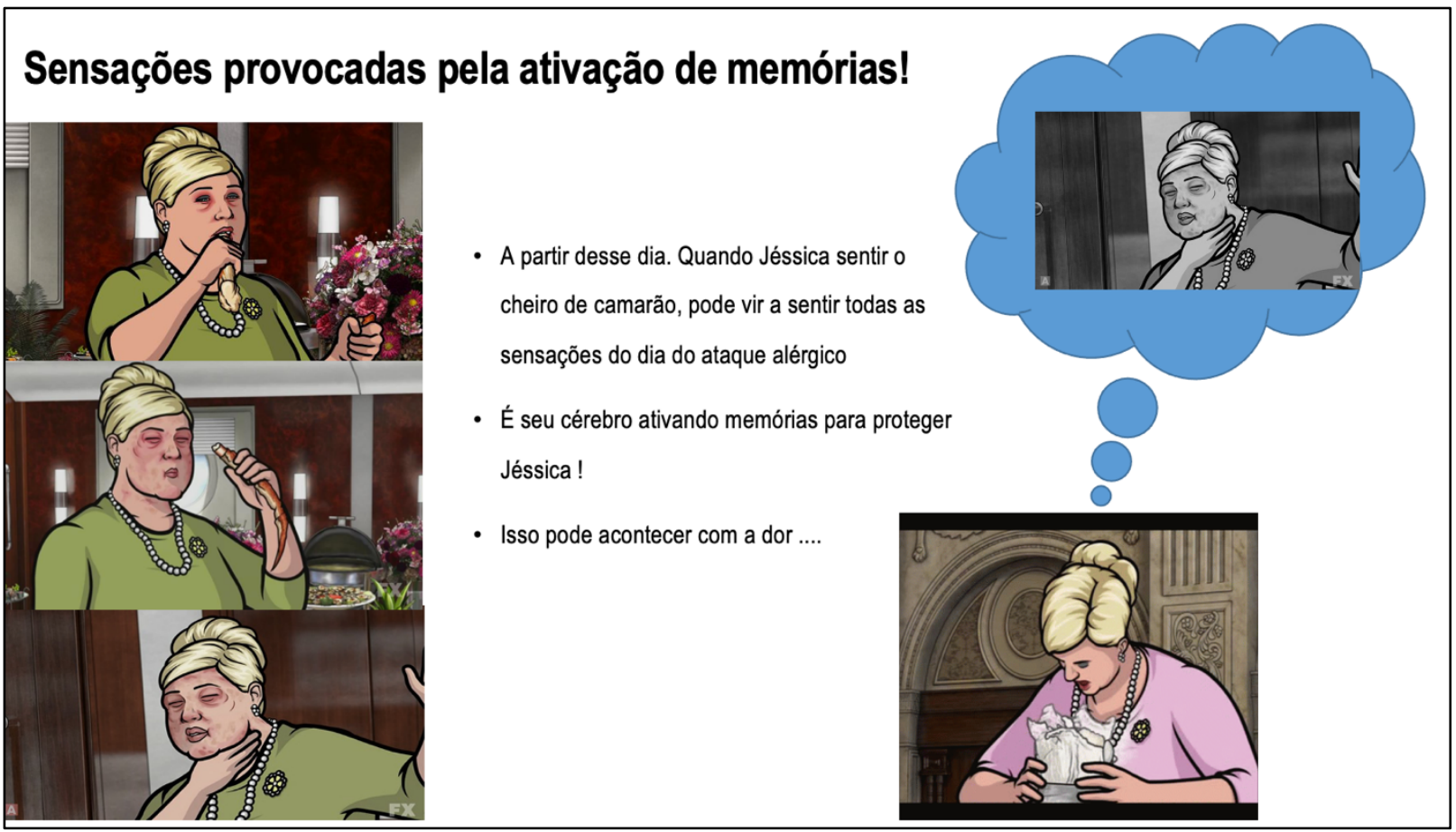

Figura 5. Slide referente ao item 5 "A saída da dor pode ser deflagrada pela memória, não apenas pela nocicepção" utilizada na sessão 1 do programa de END. 
Conceitos abordados no slide: De um modo geral, todas as informações relacionadas com nossos sentidos precisam ser avaliados pelo sistema nervoso central. E todas essas informações estão relacionadas com processos emocionais, de raciocínio e memória. Observe a Jéssica! Em um dia qualquer e sem saber que era alérgica a camarão, Jéssica estava em um jantar e decidiu experimentar o prato. E adivinha?! Ela começou a ter reações alérgicas que foram piorando a medida que ela comia o camarão... Até ela descobrir que esse era o motivo, ela passou muito mal e se sentiu sufocada.

Agora, toda vez que a Jéssica vê ou sente cheiro de camarão ou até mesmo ouve uma história sobre isso, ela pode se recordar daquele dia e tudo que ela sentiu. O contexto de sua experiência foi crítica e o cérebro da Jéssica criou memórias relacionadas a ele para sua proteção. Então, nem sempre a dor pode surgir porque existe uma lesão acontecendo... Pode se tratar de uma memória que foi construído da mesma forma que a Jéssica com camarão (Figura 5).

\subsection{Análise de Dados}

Todos os procedimentos estatísticos foram realizados de acordo com o princípios da intenção de tratar. Primeiro, conduzimos análises descritivas e inspeções de histograma para determinar a normalidade dos dados. Para avaliar as diferenças entre os grupos em resposta ao tratamento, realizamos análises de modelos lineares mistos. O modelo incluiu tratamento, tempo e a interação tratamento $\mathrm{x}$ tempo como efeitos fixos, tratamento como uma variável independente e tempo como medida repetida (imediatamente após o tratamento, 30 e 90 dias de acompanhamento). A análise estatística foi realizada por um pesquisador que não participou de nenhuma das fases da coleta de dados e recebeu os dados de forma codificada. Usamos o SPSS, versão 22.0 (IBM), para todas as análises estatísticas e definimos o valor de p em 0,05 . 


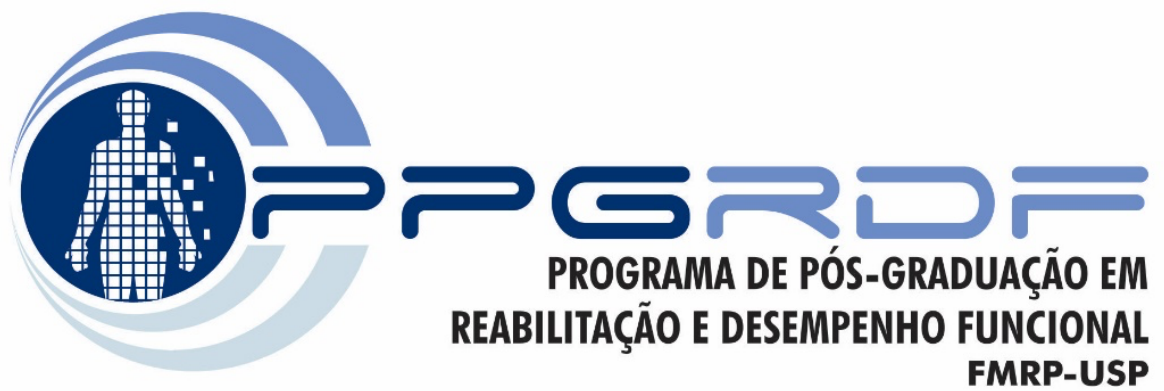

RESULTADOS

“É preciso coragem para levantar-se e falar, mas também é preciso coragem para sentar-se e ouvir."

Winston Churchill 


\section{RESULTADOS}

\section{Adesão às Intervenções e Perda dos Participantes}

Um total de 167 participantes foram inscritos e avaliados entre agosto de 2017 e setembro de 2019. Foram excluídos 62 participantes que não atenderam aos critérios de inclusão (Figura 1). Conforme descrito no cálculo do tamanho da amostra, 104 pacientes com CLBP foram randomizados em dois grupos TM $(\mathrm{n}=52)$ e TM + END $(\mathrm{n}=52)$. A análise foi realizada considerando os grupos originais atribuídos.

No grupo TM, cinco pacientes não responderam ao follow-up de 30 dias $(n=2$ recusou-se a responder as avaliações $+\mathrm{n}=3$ não aderiram ao tratamento) e 2 pacientes adicionais não compareceram aos 180 dias de seguimento $(\mathrm{n}=2$ não aderiram ao tratamento). Para o $\mathrm{TM}+\mathrm{EN}$, um paciente não concluiu o tratamento e não retornou para acompanhamento. Além disso, três pacientes desistiram no follow-up de 30 dias, um paciente no follow-up de 90 dias e dois pacientes no follow up de 180 dias (Figura 1). A taxa de abandono imediatamente após o tratamento foi de $0.009(n=1)$ e para as etapas completas do estudo observamos uma taxa de abandono de $13.46 \%$ $(\mathrm{n}=14)($ Figura 1).

\section{Características de Linha de Base dos Participantes}

A Tabela 1 mostra as características basais dos participantes (média e desvio padrão), não havendo diferença significativa entre os grupos para nenhuma variável avaliada (Tabela 1). 
Tabela 1. Descrição [média e desvio padrão (DP)] dos dados de linha de base para pacientes recrutados para o estudo. Terapia Manual (TM) vs. Terapia Manual + Educação em Neurociências $(\mathrm{TM}+\mathrm{EN})$.

\begin{tabular}{lcccc}
\hline \multicolumn{1}{c}{ Variáveis } & $\begin{array}{c}\text { Amostra total } \\
(\mathbf{n}=\mathbf{1 0 4})\end{array}$ & $\begin{array}{c}\text { TM } \\
(\mathbf{n}=\mathbf{5 2})\end{array}$ & $\begin{array}{c}\text { TM }+\mathbf{E N} \\
(\mathbf{n}=\mathbf{5 2})\end{array}$ & ANOVA, p-value \\
\hline Idade (anos) & $40.22(10.70)$ & $41.63(9.65)$ & $38.81(11.58)$ & $\mathrm{F}=(1,102)=1.82, \mathrm{p}=0.17$ \\
Peso (kg) & $71.29(14.39)$ & $70.66(13.09)$ & $71.91(14.98)$ & $\mathrm{F}=(1,102)=0.19, \mathrm{p}=0.66$ \\
Altura (m) & $1.65(0.09)$ & $1.64(0.01)$ & $1.66(0.09)$ & $\mathrm{F}=(1,102)=1.88, \mathrm{p}=0.17$ \\
IMC (kg/m $\left.{ }^{2}\right)$ & $26.28(5.04)$ & $26.37(4.54)$ & $26.18(5.54)$ & $\mathrm{F}=(1,102)=0.03, \mathrm{p}=0.84$ \\
\hline NPRS (0-10) & $6.79(2.07)$ & $6.96(2.23)$ & $6.63(1.92)$ & $\mathrm{F}=(1,102)=0.64, \mathrm{p}=0.42$ \\
ODI (0-100) & $27.65(15.34)$ & $28.61(16.53)$ & $26.69(14.14)$ & $\mathrm{F}=(1,102)=0.08, \mathrm{p}=0.77$ \\
GPE (0-11) & $-1.77(2.59)$ & $-1.61(2.65)$ & $-1.94(2.54)$ & $\mathrm{F}=(1,102)=0.41, \mathrm{p}=0.52$ \\
PSES (0-60) & $39.56(14.41)$ & $37.88(14.64)$ & $41.15(14.11)$ & $\mathrm{F}=(1,102)=1.42, \mathrm{p}=0.23$ \\
FABQ Physical (0-24) & $14.35(7.29)$ & $14.84(8.10)$ & $13.86(6.41)$ & $\mathrm{F}=(1,102)=0.46, \mathrm{p}=0.49$ \\
FABQ Work (0-42) & $19.10(11.43)$ & $20.40(11.30)$ & $17.80(11.53)$ & $\mathrm{F}=(1,102)=1.34, \mathrm{p}=0.24$ \\
PCS (0-52) & $20.14(13.15)$ & $27.23(13.77)$ & $23.68(5.01)$ & $\mathrm{F}=(1,102)=0.26, \mathrm{p}=0.60$ \\
HADS-A (0-21) & $6.43(4.57)$ & $8.57(4.36)$ & $7.50(1.51)$ & $\mathrm{F}=(1,102)=0.77, \mathrm{p}=0.38$ \\
HADS-D (0-21) & $3.43(4.83)$ & $6.59(4.19)$ & $5.01(2.23)$ & $\mathrm{F}=(1,102)=0.04, \mathrm{p}=0.82$ \\
SBST (0-9) & $4.57(2.40)$ & $5.10(2.60)$ & $4.83(0.37)$ & $\mathrm{F}=(1,102)=0.34, \mathrm{p}=0.55$ \\
\hline
\end{tabular}

NPRS = Escala Numérica de Dor, ODI = Índice de Incapacidade Lombar Oswestry, GPE = Escala de Percepção Global da Efeito, PSES = Escala de Autoeficácia Sobre Dor, FABQ = Fear-Avoidance Beliefs Questionnaire, PCS = Escala de Pensamentos Catastróficos Sobre a Dor, HADS-A = Escala de Ansiedade e Depressão Hospitalar - Ansiedade, HADS$\mathrm{D}=$ Escala de Ansiedade e, Depressão Hospitalar - Depressão, SBST $=$ StarT Back Screening Tool, $\mathrm{n}=$ tamanho da amostra, $\mathrm{Kg}=$ Quilogramas, $\mathrm{M}=$ metro, $\mathrm{IMC}=$ Índice de massa corpórea, , $\%=$ percentil $\mathrm{p}=$ significância $<0.05$

\section{Desfechos Primários}

\section{Intensidade da Dor}

Não houve interação significativa tempo vs. grupos de tratamento $(F=0.72, p=0.57)$ para a intensidade da dor. Uma diferença média pós-tratamento de 0.15 (IC95\% -0.84 a 1.14) foi observada entre os grupos (Tabela 2). 


\section{Incapacidade}

Não houve interação significativa tempo vs. grupos de tratamento $(F=0.51 \mathrm{p}=0.72)$ para incapacidade relacionada à dor lombar. Uma diferença média pós-tratamento de 1.65 (IC95\% = 3.25 a 6.56) foi observada entre os grupos (Tabela 2).

Tabela 2. Comparações entre grupos para os desfechos primários intensidade de dor e incapacidade. Terapia Manual (TM) vs. Terapia Manual + Educação em Neurociências (TM + EN).

\begin{tabular}{|c|c|c|c|c|}
\hline \multirow{2}{*}{$\begin{array}{l}\text { Desfechos } \\
\text { Primários }\end{array}$} & \multicolumn{2}{|c|}{ Média (Desvio Padrão) } & \multirow{2}{*}{$\begin{array}{c}\text { Diferença Média Estimada } \\
(95 \% \mathrm{CI}) \\
\mathbf{T M}-(\mathbf{T M}+\mathbf{E N})\end{array}$} & \multirow{2}{*}{$\begin{array}{r}\text { Efeito Interação } \\
\text { (Grupo vs. Tempo) }\end{array}$} \\
\hline & $\begin{array}{c}\mathbf{T M} \\
(\mathrm{n}=52)\end{array}$ & $\begin{array}{c}\mathbf{T M}+\mathbf{E N} \\
(\mathrm{n}=52)\end{array}$ & & \\
\hline \multicolumn{5}{|c|}{ Numeric Pain Rate Scale (NPRS), 0-10 } \\
\hline Antes tratamento & $6.96(2.23)$ & $6.63(1.92)$ & $\begin{array}{c}0.32(-0.66 \text { to } 1.32) \\
p=0.51\end{array}$ & \\
\hline $\begin{array}{l}\text { Imediatamente após } \\
\text { tratamento }\end{array}$ & $2.88(2.67)^{*}$ & $2.73(2.25)^{*}$ & $\begin{array}{c}0.15(-0.84 \text { to } 1.14) \\
\mathrm{p}=0.76\end{array}$ & \\
\hline $\begin{array}{l}30 \text { dias } \\
\text { acompanhamento }\end{array}$ & $3.42(2.43)$ & $3.05(2.24)$ & $\begin{array}{c}0.36(-0.62 \text { to } 1.35) \\
p=0.47\end{array}$ & $\begin{array}{l}F=0.72 \\
p=0.57\end{array}$ \\
\hline $\begin{array}{c}90 \text { dias } \\
\text { acompanhamento }\end{array}$ & $4.50(2.75)^{* *}$ & $3.65(2.75)$ & $\begin{array}{c}0.84(-0.14 \text { to } 1.84) \\
\mathrm{p}=0.09\end{array}$ & \\
\hline $\begin{array}{c}180 \text { dias } \\
\text { acompanhamento }\end{array}$ & $5.19(3.37)^{* *}$ & $4.00(2.82)$ & $\begin{array}{c}1.19(0.19 \text { to }-2.18) \\
\mathrm{p}=0.19\end{array}$ & \\
\hline
\end{tabular}

Oswestry Disability Index (ODI), 0-100

\begin{tabular}{|c|c|c|c|c|}
\hline Antes tratamento & $28.61(16.53)$ & $26.69(14.14)$ & $\begin{array}{c}1.92(-2.98 \text { to } 6.83) \\
p=0.44\end{array}$ & \\
\hline $\begin{array}{l}\text { Imediatamente após } \\
\text { tratamento }\end{array}$ & $14.34(12.17)^{*}$ & $12.69(11.35)^{*}$ & $\begin{array}{c}1.65(-3.25 \text { to } 6.56) \\
p=0.50\end{array}$ & \\
\hline $\begin{array}{c}30 \text { dias } \\
\text { acompanhamento }\end{array}$ & $12.15(11.68)$ & $12.07(10.73)$ & $\begin{array}{c}0.07(-4.83 \text { to } 4.98) \\
p=0.97\end{array}$ & $\begin{array}{l}F=0.51 \\
p=0.72\end{array}$ \\
\hline $\begin{array}{c}90 \text { dias } \\
\text { acompanhamento }\end{array}$ & $13.96(11.84)$ & $13.32(11.75)$ & $\begin{array}{c}0.63(-4.27 \text { to } 5.54) \\
p=0.80\end{array}$ & \\
\hline $\begin{array}{c}180 \text { dias } \\
\text { acompanhamento }\end{array}$ & $18.09(15.22)$ & $13.38(10.56)$ & $\begin{array}{c}4.71(-0.19 \text { to } 9.62) \\
p=0.06\end{array}$ & \\
\hline
\end{tabular}

\section{Desfechos Secundários}

Não houve interação significativa tempo vs. grupos de tratamento para intensidade da dor e incapacidade durante os acompanhamentos. Para a intensidade da dor, no follow-up de 30 dias a diferença média entre os grupos foi de 0.36 (IC95\% = - 0.62 a 1,35), no follow de 90 dias a diferença 
média foi de 0.84 (IC95\% = -0.14 a 1.84) e no follow-up de 180 dias, a diferença média foi de 1.19 $(\mathrm{IC} 95 \%=0.19 \mathrm{a}-2.18)$. Para incapacidade, a diferença média no follow-up de 30 dias foi de 0.07 $(\mathrm{IC} 95 \%=-4.83$ a 4.98), a a diferença média no follow-up de 90 dias foi de 0.63 (IC95\% = 4.27 a 5.54) e 4.71 (IC95\% $=-0.19$ a 9.62) no follow-up de 180 dias. Os valores médios para cada grupo para intensidade da dor e incapacidade são mostrados na tabela 2. Além disso, nenhuma interação significativa tempo vs. grupos de tratamento foi observada para o efeito global percebido $(\mathrm{F}=0.91$ $\mathrm{p}=0.45)$, autoeficácia sobre a dor $(\mathrm{F}=., 91 \mathrm{p}=0.45)$ e crenças sobre medo e evitação (FABQPhysical $=0.20 \mathrm{p}=0.93 ;$ FABQ-Work $\mathrm{F}=0.83 \mathrm{p}=0.98)($ Tabela 3$)$.

Tabela 3. Comparações entre grupos para os desfechos secundários: efeito global percebido, , autoeficácia da dor e crenças para medo-evitação. Terapia Manual (TM) vs. Terapia Manual + Educação em Neurociências (TM + EN).

\begin{tabular}{|c|c|c|c|c|}
\hline \multirow{2}{*}{$\begin{array}{l}\text { Desfechos } \\
\text { Secundários }\end{array}$} & \multicolumn{2}{|c|}{ Média (Desvio Padrão) } & \multirow{2}{*}{$\begin{array}{c}\text { Diferença Média Estimada } \\
(95 \% \mathrm{CI}) \\
\mathbf{T M}-(\mathbf{T M}+\mathbf{E N})\end{array}$} & \multirow{2}{*}{$\begin{array}{r}\text { Efeito Interação } \\
\text { (Grupo vs. Tempo) }\end{array}$} \\
\hline & $\begin{array}{c}\mathbf{T M} \\
(\mathrm{n}=52)\end{array}$ & $\begin{array}{c}\mathbf{T M}+\mathbf{E N} \\
(\mathrm{n}=52)\end{array}$ & & \\
\hline \multicolumn{5}{|c|}{ Global Perceived Effect (11 points) } \\
\hline Antes tratamento & $-1.61(2.65)$ & $-1.94(2.54)$ & $\begin{array}{c}0.32(-0.59 \text { to } 1.24) \\
p=0.48\end{array}$ & \\
\hline $\begin{array}{l}\text { Imediatamente após } \\
\text { tratamento }\end{array}$ & $2.57(2.43)^{*}$ & $2.98(1.72)^{*}$ & $\begin{array}{c}-0.40(-1.32 \text { to } 0.51) \\
p=0.38\end{array}$ & \\
\hline $\begin{array}{c}30 \text { dias } \\
\text { acompanhamento }\end{array}$ & $1.05(2.30)^{*}$ & $1.50(2.14)^{*}$ & $\begin{array}{c}-0.44(-1.36 \text { to } 0.47) \\
p=0.34\end{array}$ & $\begin{array}{l}F=0.91 \\
p=0.45\end{array}$ \\
\hline $\begin{array}{c}90 \text { dias } \\
\text { acompanhamento }\end{array}$ & $0.69(2.28)^{*}$ & $1.07(2.43)^{*}$ & $\begin{array}{c}-0.38(-1.30 \text { to } 0.53) \\
p=0.41\end{array}$ & \\
\hline $\begin{array}{c}180 \text { dias } \\
\text { acompanhamento }\end{array}$ & $0.11(2.53)^{*}$ & $1.03(2.54)^{*}$ & $\begin{array}{c}-0.92(-1.82 \text { to }-0.005) \\
p=0.49\end{array}$ & \\
\hline \multicolumn{5}{|c|}{ Pain Self-Efficacy Scale (PSES), 0-60 } \\
\hline Antes tratamento & $37.88(14.64)$ & $41.25(14.11)$ & $\begin{array}{c}-3.36(-9.87 \text { to } 3.14) \\
p=0.31\end{array}$ & \\
\hline $\begin{array}{l}\text { Imediatamente após } \\
\text { tratamento }\end{array}$ & $47.80(13.78)^{*}$ & $50.11(13.50)$ & $\begin{array}{c}-2.30(-8.82 \text { to } 4.20) \\
p=0.48\end{array}$ & \\
\hline $\begin{array}{c}30 \text { dias } \\
\text { acompanhamento }\end{array}$ & $40.00(19.18)$ & $43.28(17.53)$ & $\begin{array}{c}-3.28(-9.80 \text { to } 3.22) \\
p=0.32\end{array}$ & $\begin{array}{l}F=0.02 \\
p=0.99\end{array}$ \\
\hline $\begin{array}{c}90 \text { dias } \\
\text { acompanhamento }\end{array}$ & $39.76(18.21)$ & $42.67(18.01)$ & $\begin{array}{c}-2.90(-9.41 \text { to } 3.61) \\
\mathrm{p}=0.38\end{array}$ & \\
\hline $\begin{array}{c}180 \text { dias } \\
\text { acompanhamento }\end{array}$ & $37.57(19.33)^{*}$ & $41.05(19.13)$ & $\begin{array}{c}-3.48(-9.99 \text { to }-30.03) \\
\mathrm{p}=0.29\end{array}$ & \\
\hline
\end{tabular}




\section{Fear Avoidance Beliefs Questionnaire (FABQ-Physical), 0-42}

\begin{tabular}{ccccc}
\hline $\begin{array}{c}\text { Before intervention } \\
\text { Immediately post } \\
\text { treatment }\end{array}$ & $14.84(8.10)$ & $13.86(6.41)$ & $\begin{array}{c}0.98(-1.82 \text { to } 3.78), \\
\mathrm{p}=0.49\end{array}$ \\
30-day follow-up & $10.42(7.84)$ & $8.98(6.43)$ & $\begin{array}{c}1.44(-1.36 \text { to } 4.24), \\
\mathrm{p}=0.31\end{array}$ & $\begin{array}{c}2.61(-0.18 \text { to } 5.41), \\
\mathrm{p}=0.06\end{array}$ \\
90-day follow-up & $11.11(7.87)$ & $8.98(6.76)$ & $\begin{array}{c}2.13(-0.66 \text { to } 4.93), \\
\mathrm{p}=0.13\end{array}$ & $\begin{array}{c}\mathrm{F}=0.20 \\
\mathrm{p}=0.93\end{array}$ \\
180-day follow-up & $11.44(7.89)$ & $9.28(6.64)$ & $\begin{array}{c}2.15(-0.64 \text { to } 4.95), \\
\mathrm{p}=0.13\end{array}$ & \\
\hline
\end{tabular}

Fear Avoidance Beliefs Questionnaire (FABQ-Work), 0-24

\begin{tabular}{|c|c|c|c|c|}
\hline Antes tratamento & $20.40(11.30)$ & $17.80(11.53)$ & $2.59(-1.80$ to 7.00$), p=0.24$ & \multirow{5}{*}{$\begin{array}{l}\mathrm{F}=0.83 \\
\mathrm{p}=0.98\end{array}$} \\
\hline $\begin{array}{l}\text { Imediatamente após } \\
\text { tratamento }\end{array}$ & $15.5-(11.97)$ & $13.46(10.69)$ & $2.03(-2.36$ to 6.44$), p=0.36$ & \\
\hline $\begin{array}{c}30 \text { dias } \\
\text { acompanhamento }\end{array}$ & $14.50(11.74)$ & $13.17(11.20)$ & $1.32(-3.07$ to 5.73$), \mathrm{p}=0.55$ & \\
\hline $\begin{array}{c}90 \text { dias } \\
\text { acompanhamento }\end{array}$ & $15.25(11.17)$ & $13.44(10.88)$ & $1.18(-2.59$ to 6.21$), \mathrm{p}=0.42$ & \\
\hline $\begin{array}{c}180 \text { dias } \\
\text { acompanhamento }\end{array}$ & $14.34(12.25)$ & $13.42(11.45)$ & $0.92(-3.48$ to 5.32$), p=0.68$ & \\
\hline
\end{tabular}

\section{Análises Intragrupo desfechos primários}

Considerando a análise intragrupo, observamos um efeito principal significativo do tempo para ambos os desfechos primários.

No grupo TM, foi encontrada uma diminuição significativa na intensidade da dor no póstratamento $(\mathrm{MD}=-4.07 \mathrm{IC} 95 \%=-2.65 \mathrm{a}-5.5, \mathrm{p}<0.001)$. Também foram encontradas diferenças significativas na intensidade da dor aos $90(\mathrm{MD}=1.61 \mathrm{IC} 95 \%=-3.04 \mathrm{a}-0.19, \mathrm{p}=0.01)$ e 180 dias de follow-up $(\mathrm{MD}=2.30 \mathrm{IC} 95 \%=-3.04 \mathrm{a}-0.19, \mathrm{p}<0.001)$ quando comparados aos valores do pós-tratamento imediato, mostrando aumento significativo da dor nos acompanhamentos. Para o grupo TM + EN, também foi observada uma redução significativa na intensidade da dor (MD = 3.9 IC95\% $=-2.47 \mathrm{a}-5.32, \mathrm{p}<0.001)$ imediatamente após o tratamento. No entanto, para o grupo TM + EN, não observamos nenhuma diferença significativa para a intensidade da dor em todos os acompanhamentos quando comparados aos valores de pós-tratamento imediato (follow-up de 30 
dias, $\mathrm{MD}=-0.32 \mathrm{IC} 95 \%=-1,75$ a $1.09, \mathrm{p}=1$; follow-up de 90 dias, $\mathrm{MD}=-0.92$ IC95\% $=-2.34$ a $0.50, \mathrm{p}=0.68$ e follow-up de 180 dias, $\mathrm{MD}=-1.2$ IC95\% $=-2.69$ a $0.15, \mathrm{p}=0.12$ ), mostrando um efeito consistente de longo prazo na redução da dor, conforme observado imediatamente após o tratamento.

No entanto, para ambos os grupos, mostramos uma diminuição significativa na percepção da incapacidade no pós-tratamento (grupo TM $\mid \mathrm{MD}=-14.27$ IC95\% $=-7.22 \mathrm{a}-21.3, \mathrm{p}<0.001 \mathrm{e}$ $\mathrm{TM}+\mathrm{END} \mid \mathrm{MD}=-14 \mathrm{IC95 \%}=-21.7 \mathrm{a}-7.60, \mathrm{p}<0.001)$. Nenhuma diferença significativa entre os valores pós-tratamento vs. os valores de acompanhamento para o grupo TM (follow-up de 30 dias, $\mathrm{MD}=2.1 \mathrm{IC} 95 \%=-4.85$ a $9.23 \mathrm{p}=1$; follow-up de 90 dias, $\mathrm{MD}=0.38, \mathrm{IC} 95 \%=-6.66 \mathrm{a}$ $7.4, p=1$ e follow-up de 180 dias, $\mathrm{MD}=-3.75, \mathrm{IC} 95 \%=-10.79$ a $3.29, \mathrm{p}=1$ ) e para o grupo TM + END (follow-up de 30 dias, $\mathrm{MD}=0.61 \mathrm{IC} 95 \%=-6.43$ a 7.66, $\mathrm{p}=1$; follow-up de 90 dias, MD $=-0.63$ IC95\% $=-7.68$ a $6.41, \mathrm{p}=1$ e follow-up de 180 dias, $\mathrm{MD}=-0.69 \mathrm{IC} 95 \%=-7.73$ a 6.35 , $\mathrm{p}=1$ ). Desta forma, ambos os grupos mostraram uma manutenção consistente da diminuição da percepção da deficiência observada imediatamente após o tratamento.

\section{Análises Intragrupo desfechos secundários}

Considerando a análise intragrupo, observamos um efeito principal significativo do tempo para os desfechos secundários.

No grupo TM, foi encontrada uma melhora significativa na percepção global de efeito no pós-tratamento $(\mathrm{MD}=-4.19, \mathrm{IC} 95 \%=-5.51 \mathrm{a}-2.87, \mathrm{p}<0.001)$. Também foram encontradas diferenças significativas na percepção global de efeito aos $30(\mathrm{MD}=1.51$, IC95\% $=0.20$ a 2.83, p $=0.012), 90(\mathrm{MD}=1.88 \mathrm{IC} 95 \%=0.56$ a 3.20, $\mathrm{p}=0.001)$ e 180 dias de follow-up $(\mathrm{MD}=2.46$, IC95\% $=1.14$ a $3.78, \mathrm{p}<0.001)$ quando comparados aos valores do pós-tratamento imediato, mostrando diminuição significativa da percepção global de efeito nos acompanhamentos.

Para o grupo TM + END, também foi observada uma melhora significativa na percepção 
global de efeito $(\mathrm{MD}=-4.92, \mathrm{IC} 95 \%=-6.24 \mathrm{a}-3.60, \mathrm{p}<0.001)$ imediatamente após o tratamento. Da mesma forma, também foram encontradas reduções significativas na percepção global de efeito aos $30(\mathrm{MD}=1.48, \mathrm{IC} 95 \%=0.16$ a $2.79, \mathrm{p}=0.016), 90(\mathrm{MD}=1.90, \mathrm{IC} 95 \%=0.58$ a $3.22, \mathrm{p}=$ $0.001)$ e 180 dias de follow-up $(\mathrm{MD}=1.94$, IC95\% $=0.62$ a $3.26, \mathrm{p}<0.001)$ quando comparados aos valores do pós-tratamento imediato, mostrando diminuição significativa da percepção global de efeito nos acompanhamentos.

Considerando crenças de medo-evitação relacionadas ao exercício no grupo TM, não observamos nenhuma diferença significativa no pós-tratamento $(\mathrm{MD}=3.34, \mathrm{IC} 95 \%=-0.67$ a 7.36 , $\mathrm{p}=0.19$ ) ou acompanhamentos (follow-up de 30 dias, $\mathrm{MD}=1.07$, IC95\% $=-2.94$ a $5.09, \mathrm{p}=1$; follow-up de 90 dias, $\mathrm{MD}=0.38, \mathrm{IC} 95 \%=-3.63$ a 4.40, $\mathrm{p}=1$ e follow-up de 180 dias, $\mathrm{MD}=0.58$, IC95\% = -3.96 a 4.08, p = 1), mostrando ausência de efeito imediato ou de longo prazo da TM na redução das crenças de medo-evitação relacionadas ao exercício.

Para o grupo TM + END, foi encontrada uma diminuição significativa nas crenças de medoevitação relacionadas ao exercício no pós-tratamento $(\mathrm{MD}=4.98, \mathrm{IC} 95 \%=0.95$ a 9.00, p $=0.05)$. Nenhuma outra diferença significativa foi observada nos acompanhamentos quando comparados aos valores de pós-tratamento imediato (follow-up de 30 dias, $\mathrm{MD}=-0.96$, IC95\% $=-4,11$ a 3.92 , $\mathrm{p}=1$; follow-up de 90 dias, $\mathrm{MD}=-0.96, \mathrm{IC} 95 \%=-4,11$ a $3.92, \mathrm{p}=1$ e follow-up de 180 dias, MD $=-0.40$, IC95\% $=-4.42$ a 3.61, p = 1), mostrando um efeito consistente de longo prazo na redução das crenças de medo-evitação relacionadas ao exercício, conforme observado imediatamente após o tratamento.

Para as crenças de medo-evitação relacionadas ao trabalho, nenhuma diferença significativa foi observada em nenhum dos grupos no pós-tratamento $(\mathrm{TM} \mid \mathrm{MD}=4.90, \mathrm{IC} 95 \%=-1.41$ a 11.22 , $\mathrm{p}=0.29 ; \mathrm{TM}+\mathrm{END} \mid \mathrm{MD}=4.34, \mathrm{IC} 95 \%=-1.97 \mathrm{a} 10.66, \mathrm{p}=0.53)$ ou acompanhamentos $(\mathrm{TM} \mid$ follow-up de 30 dias, $\mathrm{MD}=1.00, \mathrm{IC} 95 \%=-5.32$ a $7.32, \mathrm{p}=1$; follow-up de 90 dias, $\mathrm{MD}=0.25$, IC95\% $=-6.07$ a $6.57, \mathrm{p}=1$ e follow-up de 180 dias, $\mathrm{MD}=1.15, \mathrm{IC} 95 \%=-5.16$ a $7.47, \mathrm{p}=1 ; \mathrm{TM}$ 
+ END $\mid$ follow-up de 30 dias, $\mathrm{MD}=0.28, \mathrm{IC} 95 \%=-6.03$ a $6.60, \mathrm{p}=1$; follow-up de 90 dias, MD $=0.01, \mathrm{IC} 95 \%=-6.30$ a $6.34, \mathrm{p}=1$ e follow-up de 180 dias, $\mathrm{MD}=0.03, \mathrm{IC} 95 \%=-6.28$ a $6.35, \mathrm{p}$ =1), mostrando ausência de efeito imediato ou de longo prazo da TM ou da TM + END na redução das crenças de medo-evitação relacionadas ao trabalho.

Considerando autoeficácia sobre a dor no grupo TM, foi encontrado aumento significativo no pós-tratamento imediato em relação ao baseline $(\mathrm{MD}=-9.92, \mathrm{IC} 95 \%=-19.27$ a $-0.55, \mathrm{p}=$ 0.029). Nenhuma outra diferença significativa foi observada nos acompanhamentos de 30 e 90 dias quando comparados aos valores de pós-tratamento imediato (follow-up de 30 dias, $\mathrm{MD}=7.80$, IC95\% $=-1,54$ a 17.15, $\mathrm{p}=0.18$; follow-up de 90 dias, $\mathrm{MD}=8.03$, I C95\% $=-1,30$ a $17.38, \mathrm{p}=$ 0.15) mostrando um efeito consistente de melhora na autoeficácia sobre a dor. Aos 180 dias, uma redução significativa foi observada $(\mathrm{MD}=10.23, \mathrm{IC} 95 \%=0.88$ a $19.58, \mathrm{p}=0.02)$, mostrando diminuição da autoeficácia sobre a dor em longo prazo.

Para o grupo TM + END, não observamos nenhuma diferença significativa no póstratamento $(\mathrm{MD}=-8.86 \mathrm{IC} 95 \%=-18.21$ a $0.48, \mathrm{p}=0.07)$ ou acompanhamentos (follow-up de 30 dias, $\mathrm{MD}=6.82 \mathrm{IC} 95 \%=-2.52$ a 16.17, $\mathrm{p}=0.40$; follow-up de 90 dias, $\mathrm{MD}=7.44 \mathrm{IC} 95 \%=-1.90$ a $16.79, \mathrm{p}=0.25$ e follow-up de 180 dias, $\mathrm{MD}=9.05 \mathrm{IC} 95 \%=-0.29$ a $18.40, \mathrm{p}=0.06)$ mostrando ausência de efeito imediato ou de longo prazo da TM + END na melhora da autoeficácia sobre a dor. 


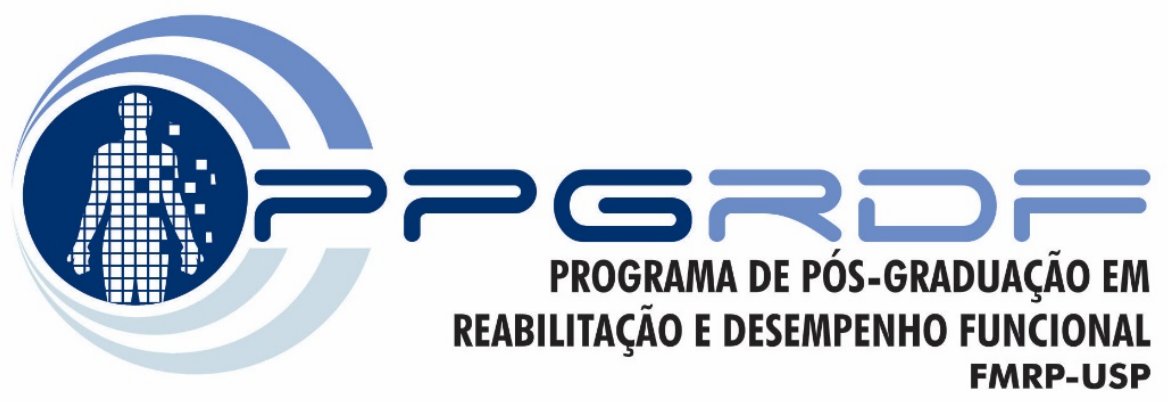

DISCUSSÃO

“O temor do Senhor é o princípio do

conhecimento, mas os insensatos desprezam a

sabedoria e a disciplina.'

Provérbios 1:7

Claude Lévi-Strauss 


\section{DISCUSSÃO}

Nosso estudo comparou o efeito adicional da END à TM na intensidade da dor e incapacidade em pacientes com DLC. Nossos resultados não mostraram nenhuma diferença entre os grupos. Não confirmamos nossa hipótese levantada a priori de que a associação entre Educação em Neurociência da Dor + Terapia Manual apresentaria efeitos maiores para a intensidade da dor e incapacidade do que uma intervenção focada apenas na Terapia Manual.

Não há nenhum estudo anterior que comparou o efeito adicional da END à TM na intensidade da dor e incapacidade em DLC. No entanto, há estudos em que a educação para a dor + TM foi comparada com a TM + educação com foco na biomecânica (Louw et al, 2017) e um estudo que investigou o efeito adicional de um programa de terapia cognitivocomportamental para uma intervenção de cuidado padrão (tratamentos físicos) (Petrozzi et al, 2019). Assim como em nossos achados, nenhuma diferença entre os grupos foi observada para incapacidade ou intensidade da dor em ambos os estudos.

Uma outra diferença do nosso estudo foi a utilização de uma RPCm na tentativa de incluir em ambos os grupos de nossa amostra pacientes mais responsivos à TM na tentativa de atender as expectativas em relação ao tratamento convencionalmente esperado, além de garantir um possível destaque os efeitos de uma abordagem hands off. Mas apesar do entusiasmo na tentativa de propor essas regras, o estado atual sugere que esta abordagem pode não ser ideal para identificar pacientes responsivos à TM (Bialoski et al, 2018). Uma revisão sistemática avaliou RPCs diagnósticas, prescritivas e prognósticas no tratamento fisioterapêutica da lombar e destacou a falta de estudos de impacto sugerindo que as evidências encontradas não suportam a a aplicação clínica direta e confiável das RPCs identificadas (Haskins et al, 2011). Muito embora a revisão de Stanton et al. (2010) corrobore com o corpo de evidências sugerindo cautela na aplicação das RPCs, um estudo (Flynn et al, 2002) é descrito como o único que passou por uma validação em um ensaio controlado e pode 
ser considerado para aplicação clínica. Essa foi a RPC adotada nesse estudo com as adequações sugeridas por Dougherty et al. (2014) para inclusão de pacientes crônicos.

Por outro lado, nossos resultados não estão de acordo com dois outros estudos publicados anteriormente (Beltran-Alacreu et al, 2015; Saracoglu et al, 2020). Um achado anterior (Beltran-Alacreu et al, 2015) mostrou que pacientes com dor cervical crônica submetidos a END (associada a TM ou TM + exercício) apresentaram maiores efeitos para incapacidade e intensidade da dor do que o grupo que recebeu apenas TM. Além disso, no estudo de Saracoglu et al. (2020) três grupos de intervenção foram comparados: END + TM + programa de exercícios em casa (PEC), outro grupo que recebeu TM + PEC e o terceiro grupo que recebeu apenas PEC. O grupo que recebeu a combinação END +TM + PEC apresentou redução significativa da intensidade da dor quando comparado aos grupos submetidos a TM + PEC ou apenas PEC. No entanto, para ambos os grupos submetidos a TM com ou sem END, foi relatada uma redução significativa da incapacidade quando comparado ao grupo submetido apenas ao PEC.

A principal razão para a discrepância entre nossos resultados e esses achados anteriores (Beltran-Alacreu et al, 2015, Saracoglu et al, 2020) poderia ser explicada pelo pequeno tamanho da amostra incluída em ambos os estudos (tamanho total da amostra, $n=45$ [Beltran -Alacreu et al, 2015] e $\mathrm{n}=69$ [Saracoglu et al, 2020]). Amostras pequenas podem aumentar a chance de erro do tipo II e, portanto, a falta de poder estatístico para refutar a hipótese nula (Rubinstein et al, 2014). Além disso, a diferença pós-tratamento relatada entre os grupos no estudo que inscreveu pacientes com DLC foi de apenas $1.37(\mathrm{END}+\mathrm{TM}+\mathrm{PEC}=3.05$ e TM + PEC $=4.42)($ Saracoglu et al, 2020), o que poderia ser considerado um diferença estatística, mas não uma diferença clinicamente relevante (Ostelo et al, 2008, Maughan e Lewis, 2010).

Um outro ensaio clínico comparou os efeitos de diferentes técnicas de mobilização (Maitland vs Mulligan) para intensidade da dor, incapacidade e diversos aspectos psicológicos 
em pacientes com dor cervical crônica (Alansari et al, 2021). Um desses aspectos eram crenças de medo-evitação que apresentou diferença significativa na análises intragrupo a favor do grupo Maitland (FABQ-PA, p =0.04; FABQ-W, p = 0.02) embora não tivesse diferenças significativas entre as técnicas (FABQ-PA, $\mathrm{p}=0.27$; FABQ-W, $\mathrm{p}=0.31$ ). Em nosso estudo, no que se refere a crenças de medo-evitação relacionadas ao trabalho, nenhuma diferença significativa ou clinincamente relevante (MCID 7 pontos) foi encontrada (Monticone et al, 2020) para ambos os grupos no pós-tratamento ou acompanhamentos. Curiosamente, um dos nossos critérios de elegibilidade contemplavam pontuação FABQ Work < 19 (Flynn et al, 2002; Dougherty et al, 2014) como parte de uma RPCm excluindo da amostra pacientes com escores mais elevados e, possivelmente, com mais chance de mudança. Para crenças de medoevitação relacionadas ao exercício, uma diferença de 4.98 foi observada no pós-tratamento imediato do grupo TM + END. Essa diferença é superior ao MCID de 4 pontos (Monticone et al, 2020) e portanto, clinicamente relevante. Nenhuma mudança foi observada no grupo TM isolada. Nesse caso, nossos resultados sugerem que o programa de END tenha contribuído mais especificamente para alterar crenças relacionadas ao movimento.

Crenças de medo-evitação, percepção global de efeito e autoeficácia da dor não são frequentemente avaliados como medidas de desfecho nas abordagens de tratamento para dor lombar crônica. Um estudo comparou o efeito adicional de um programa de END à um programa de exercícios terapêuticos em pacientes com com DLC (Bodes Pardo et al, 2018). Nesse estudo, mudanças significativas com grande tamanho de efeito foram encontradas à favor do grupo END + exercícios em impressão global de mudança do paciente e cinesiofobia (Bodes Pardo et al, 2018).

Pode-se argumentar que a administração de END associada a TM poderia trazer informações conflitantes aos pacientes e explicar a falta de efeito quando o END está associada a TM. Os programas de END são projetados para ressignificar a dor e motivar os 
pacientes a estratégias de autocuidado da dor. Os pacientes são encorajados a se manter ativos apesar da dor e se envolver em programas de exercícios rotineiramente. Por outro lado, TM ou abordagens de terapia manual são reconhecidas como tratamentos passivos (Rhon e Deyle, 2021). Na Fisioterapia, o termo passivo é usado para se referir a um tratamento no qual o paciente desempenha um papel passivo (Rhon e Deyle, 2021). Como resultado, o uso de estratégias de tratamento sem intervenção para o tratamento da dor musculoesquelética crônica é recomendado por diretrizes internacionais (Lin et al, 2020) e a administração de TM (particularmente como tratamento principal ou terapia isolada) pode estimular um comportamento de dependência do sistema de saúde que pode ser entendida como contraditória no contexto da EN.

Entretanto, não podemos deixar de considerar que o programa de END administrado pode não ter sido eficaz para alterar especificamente os desfechos primários controlados nesse estudo. (intensidade de dor e incapacidade). Uma revisão sistemática anterior com metaanálise (Wood e Hendrick et al, 2019) mostrou que a END associada a outros tratamentos (baseados em movimento) mostrou um pequeno efeito na intensidade da dor e na incapacidade em pacientes com DLC. Considerando que a END está focada na mudança cognitiva e de crenças, pode-se argumentar que estudos sobre a eficácia da END devem adotar desfechos que contemplem fatores cognitivos. No entanto, também avaliamos a autoeficácia da dor e as crenças de medo e evitação nesse estudo, e não encontramos nenhuma diferença entre os grupos nessas variáveis. Uma das principais limitações do nosso estudo foi não investigar o conhecimento sobre a dor (Neurophysiology of Pain Questionnaire - Catley et al, 2013) e a mudança nas crenças sobre a dor (Survey of Pain Attitudes - Jensen et al, 1994). Novos estudos investigando quais os conteúdos mais adequados e as estratégias utilizadas nos programas de END são necessários. 
Ambos os grupos mostraram reduções clinicamente relevantes na intensidade da dor e melhora na incapacidade (Ostelo et al, 2008). Dessa forma, nossos achados mostraram que um programa de END associado à TM não trouxe nenhum efeito adicional para a intensidade da dor, incapacidade, crenças de medo e evitação, efeito global percebido e autoeficácia da dor. Curiosamente, nossos resultados mostraram que a diferença média na intensidade da dor no grupo submetido a TM isolada no seguimento de 180 dias em comparação com a avaliação pós-tratamento foi de 2.31, o que pode ser considerado diferença estatística e clinicamente relevante, atingindo 2 unidades descritas anteriormente como MCID (Ostelo et al, 2008). Porém, no grupo submetido a TM + EN, não foi encontrada diferença intragrupo para a intensidade da dor nos acompanhamentos de 90 e 180 dias em relação à intensidade da dor pós-tratamento imediato. A diferença média da intensidade da dor no grupo submetido ao TM + END foi de 1.12, o que não foi estatisticamente e nem clinicamente relevante. Tal resultado sugere que a associação de TM + END pode apresentar um melhor efeito de longo prazo no controle da intensidade da dor.

Em nosso estudo, não foi encontrada nenhuma diferença entre os grupos para os desfechos secundários: efeito global percebido, crenças de medo-evitação e autoeficácia da dor. Uma revisão sistemática anterior com meta-análise (Watson et al, 2019) demonstrou que a END mostrou um efeito na catastrofização da dor e medo do movimento em pacientes com dor musculoesquelética crônica, apesar de ser um efeito pequeno. Sugerimos que estudos futuros devem incluir a avaliação da catastrofização da dor e medo do movimento ou medo da dor como resultados em ECRs.

Melhoras clinicamente relevantes foram observadas tanto no grupo TM quanto no grupo TM + END para percepção global de efeito no pós-tratamento imediato. As mudanças dos scores médios de ambos os grupos foram superiores aos 2 pontos considerados como MCID por Kamper et al. (2009) e se mantiveram ao longo tempo. Apenas aos 180 dias de 
acompanhamento, uma mudança de 2.46 pontos foi observada no grupo TM caracterizando mudança clinicamente relevante. Uma diferença de 9.92 pontos foi observada no póstratamento do grupo TM para o desfecho autoeficácia sobre a dor. Como a MCID para autoeficácia é de 9 pontos (Maughan e Lewis, 2010), esse diferença pode ser considerada como clinicamente relevante. Já no grupo TM + END, a mudança só foi observada aos 180 dias quando comparadas com o pós-tratamento imediato. Mesmo que esses resultados apresentam mudanças nos desfechos nas análise intragrupos, ressaltamos que nenhuma diferença estatisticamente significativa foi observada entre eles.

O presente estudo apresenta várias limitações: 1) Não foi possível cegar os terapeutas que administraram as intervenções, mas minimizamos esse problema adotando o cegamento do pesquisador envolvido na avaliação dos resultados; 2) Não avaliamos o conhecimento adquirido dos pacientes após o programa de EN, estudos futuros deveriam adotar uma estratégia de controle para o aprendizado e 3) TM e END foram administrados de forma prescritiva e não pragmaticamente, talvez essas intervenções devam ser customizadas para atender propósitos individuais. 


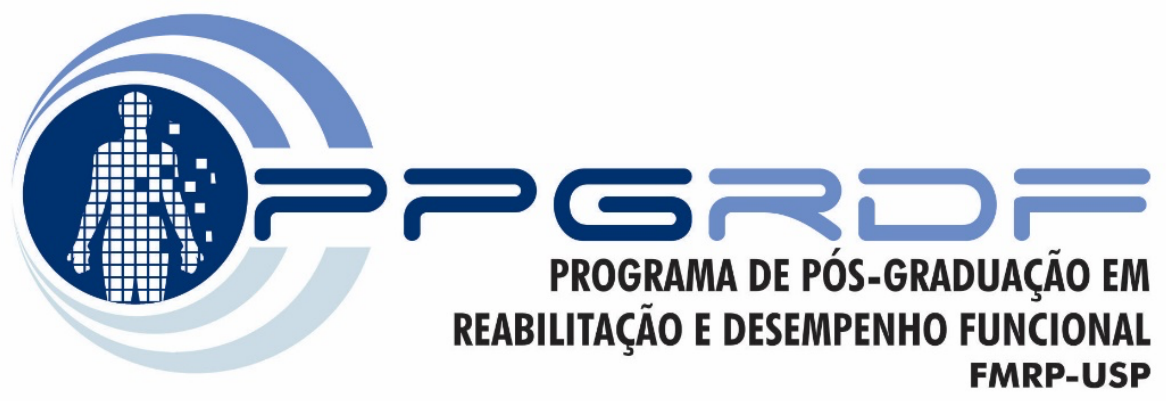

CONCLUSÃO

“Seja o que você deseja parecer."

Socrates

Benjamin Disraeli 


\section{CONCLUSÃO}

No presente estudo não foi encontrado nenhum efeito adicional da END à TM para a intensidade da dor e incapacidade em pacientes com DLC. Os resultados deste estudo sugerem que a adição de END à TM não trouxe nenhum efeito adicional para a intensidade da dor e incapacidade em pacientes com DLC em curto prazo. No entanto, encontramos um maior efeito estatisticamente e clinicamente relevante para a intensidade de dor a longo prazo no grupo submetido à combinação de estratégias (END + TM) quando comparada à TM isolada. 


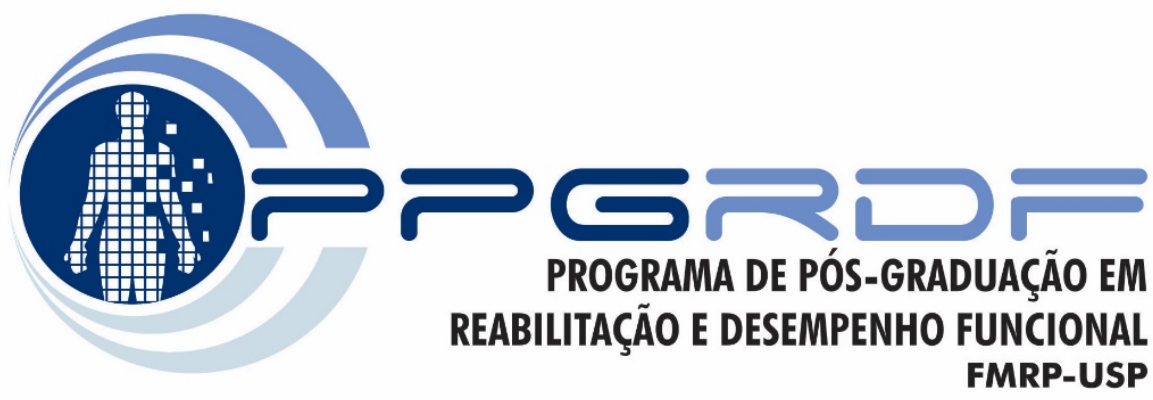

REFERÊNCIAS

“... a sabedoria preserva a vida de quem a possui."

Eclesiastes 7:12 
Referências

\section{REFERÊNCIAS}

1. Abreu AM, Faria CDCM, Cardoso SMV, Teixeira-Salmela LF. The Brazilian version of the Fear Avoidance Beliefs Questionnaire. Cad Saúde Pública 2008; 24: 615-623.

2. Alansari SM, Youssef EF, Shanb AA. Efficacy of manual therapy on psychological status and pain in patients with neck pain. A randomized clinical trial. Saudi Med J. 2021 Jan;42(1):82-90. doi: 10.15537/smj.2021.1.25589. PMID: 33399175; PMCID: PMC7989325.

3. Baldwin ML, Butler RJ, Johnson WG, Cote P. Self-reported severity measures as predictors of return-to-work outcomes in occupational back pain. J Occup Rehabil. 2007; 17:683-700.

4. Beltran-Alacreu H, L.pez-de-Uralde-Villanueva I, Fernandez- Carnero J, La Touche R 2015 Manual therapy, therapeutic patient education, and therapeutic exercise, an effective multimodal treatment of nonspecific chronic neck pain: A randomized controlled trial. American Journal of Physical Medicine \& Rehabilitation 94: 887897.

5. Bialosky JE, Beneciuk JM, Bishop MD, Coronado RA, Penza CW, Simon CB, George SZ. Unraveling the Mechanisms of Manual Therapy: Modeling an Approach. J Orthop Sports Phys Ther. 2018 Jan;48(1):8-18. doi: 10.2519/jospt.2018.7476. Epub 2017 Oct 15. PMID: 29034802.

6. Bialosky JE, Bishop MD, Price DD, Robinson ME, George SZ. The mechanisms of manual therapy in the treatment of musculoskeletal pain: A comprehensive model. Man Ther. 2009;14(5):531-538.

7. Bialosky JE, Bishop MD, Robinson ME, Zeppieri G Jr, George SZ. Spinal manipulative therapy has an immediate effect on thermal pain sensitivity in people with low back pain: a randomized controlled trial. Phys Ther. 2009; 89(12):1292303.

8. Bigos S, Bowyer O, Braen G, et al. Acute low back problems in adults. Rockville, MD: Agency for Health Care Policy and Research, Public Health Service, U.S. Department of Health and Human Services, 1994.

9. Bjelland I, Dahl AA, Haug TT, Neckelmann D. 2002. The validity of the Hospital Anxiety and Depression Scale. An updated literature review. Journal of Psychosomatic Research. 52:69-77. 
Referências

10. Bodes Pardo G, Lluch Girbés E, Roussel NA, Gallego Izquierdo T, Jiménez Penick V, Pecos Martín D. Pain Neurophysiology Education and Therapeutic Exercise for Patients With Chronic Low Back Pain: A Single-Blind Randomized Controlled Trial. Arch Phys Med Rehabil. 2018 Feb;99(2):338-347. doi: 10.1016/j.apmr.2017.10.016. Epub 2017 Nov 11. PMID: 29138049.

11. Booth J, Moseley GL, Schiltenwolf M, Cashin A, Davies M, Hübscher M. Exercise for chronic musculoskeletal pain: A biopsychosocial approach. Musculoskeletal Care. 2017 Mar 30.

12. Borkan JM, Koes B, Reis S, Cherkin DC. A report from the Second International Forum for Primary Care Research on Low Back Pain: reexamining priorities. Spine (Phila Pa 1976). 1998;23:1992-1996.

13. Bronfort G, Haas M, Evans RL, Bouter LM. Efficacy of spinal manipulation and mobilization for low back pain and neck pain: a systematic review and best evidence synthesis. Spine J. 2004; 4:335-56. [PubMed: 15125860]

14. Butler D, Moseley G. Explain pain. Adelaide: Noigroup; 2013 (Portuguese version).

15. Catley MJ, O'Connell NE, Moseley GL. How good is the neurophysiology of pain questionnaire? A Rasch analysis of psychometric properties. J Pain. 2013 Aug;14(8):818-27. doi: 10.1016/j.jpain.2013.02.008.

16. Chaparro LE, Furlan AD, Deshpande A, et al. Opioids compared to placebo or other treatments for chronic low-back pain. Cochrane Database Syst Rev 2013;8:CD004959.

17. Chou R, Qaseem A, Snow V, et al. Diagnosis and treatment of low back pain: a joint clinical practice guideline from the American College of Physicians and the American Pain Society. Ann Intern Med. 2007;147(7):478-491.

18. Clark BC, Thomas JS, Walkowski SA, Howell JN. The biology of manual therapies. J Am Osteopath Assoc. 2012 Sep;112(9):617-29. PMID: 22984235.

19. Clarke CL, Ryan CG, Martin DJ. Pain neurophysiology education for the management of individuals with chronic low back pain: A systematic review and meta-analysis. Man Ther. 2011;16(6):544-549.

20. Cleland JA, Childs JD, Fritz JM, Whitman JM, Eberhart SL. Development of a clinical prediction rule for guiding treatment of a subgroup of patients with neck pain: use of thoracic spine manipulation, exercise, and patient education. Phys Ther. 2007;87:9-23. https://doi. org/10.2522/ptj.20060155 


\section{Referências}

21. Cohen SP, Vase L, Hooten WM. Chronic pain: an update on burden, best practices, and new advances. Lancet. 2021 May 29;397(10289):2082-2097. doi: 10.1016/S0140-6736(21)00393-7. PMID: 34062143.

22. Cook C, Learman K, Showalter C, Kabbaz V, O'Halloran B. Early use of thrust manipulation versus non-thrust manipulation: a randomized clinical trial. Man Ther. 2013;18:191-198. https:// doi.org/10.1016/j.math.2012.08.005

23. Coronado RA, Gay CW, Bialosky JE, Carnaby GD, Bishop MD, George SZ. Changes in pain sensitivity following spinal manipulation: A systematic review and meta-analysis. J Electromyogr Kinesiol. 2012; 22(5):752-67.

24. Costa LO, Maher CG, Latimer J, Ferreira PH, Ferreira ML, Pozzi GC, Freitas LM. Clinimetric testing of three self-report outcome measures for low back pain patients in Brazil: which one is the best? Spine (Phila Pa 1976) 2008; 33:2459-63.

25. Coulter I, Hurwitz E, Adams A, et al. The appropriateness of manipulation and mobilization of the cervical spine. RAND. 1996 MR-781-CCR.

26. D’Mello R, Dickenson A. Spinal cord mechanisms of pain. British Journal of Anaesthesia. 2008;101(1):8-16.

27. de Oliveira RF, Liebano RE, Costa L da C, Rissato LL, Costa LO. Immediate effects of region-specific and non-region-specific spinal manipulative therapy in patients with chronic low back pain: a randomized controlled trial. Phys Ther. 2013; 93(6):748-56.

28. de Santana Josimari Melo, Perissinotti Dirce Maria Navas, Oliveira Junior José Oswaldo de, Correia Luci Mara França, Oliveira Célia Maria de, Fonseca Paulo Renato Barreiros da. Revised definition of pain after four decades. BrJP [Internet]. 2020 Sep [cited 2021 May15];3(3):197-198.Available from: http://www.scielo.br/scielo.php?script=sci_arttext\&pid=S259531922020000300197 \&lng=en. Epub Sep 21, 2020. https://doi.org/10.5935/2595-0118.20200191.

29. Delitto A, Erhard RE, Bowling RW. A treatment-based classification approach to low back syndrome: identifying and staging patients for conservative management. Phys Ther 1995;75:470-89.

30. Deyo RA, Mirza SK, Turner JA, Martin BI. Overtreating chronic back pain: time to back off? J Am Board Fam Med JABFM. 2009;22(1):62-8. https://doi.org/10.3122/jabfm.2009.01.080102. 


\section{Referências}

31. Dougherty PE, Karuza J, Savino D, Katz P. Evaluation of a modified clinical prediction rule for use with spinal manipulative therapy in patients with chronic low back pain: a randomized clinical trial. Chiropr Man Therap. 2014;22(1):41.

32. Dworkin RH, Turk DC, Farrar JT, Haythornthwaite JA, Jensen MP, Katz NP, Kerns RD, Stucki G, Allen RR, Bellamy N, Carr DB, Chandler J, Cowan P, Dionne R, Galer BS, Hertz S, Jadad AR, Kramer LD, Manning DC, Martin S, McCormick CG, McDermott MP, McGrath P, Quessy S, Rappaport BA, Robbins W, Robinson JP, Rothman M, Royal MA, Simon L, Stauffer JW, Stein W, Tollett J, Wernicke J, Witter J; IMMPACT. Core outcome measures for chronic pain clinical trials: IMMPACT recommendations. Pain 2005; 113:9-19.

33. Flynn T, Fritz J, Whitman J, et al. A clinical prediction rule for classifying patients with low back pain who demonstrate short-term improvement with spinal manipulation. Spine (Phila Pa 1976). 2002;27(24):2835-2843.

34. Gallagher L, McAuley J, Moseley GL. A randomized-controlled trial of using a book of metaphors to reconceptualize pain and decrease catastrophizing in people with chronic pain. Clin J Pain. 2013; 29(1):20-5.

35. Gatchel RJ, Peng YB, Peters ML, Fuchs PN, Turk DC. The biopsychosocial approach to chronic pain: Scientific advances and future directions. Psychological Bulletin. 2007;133(4):581.

36. GBD 2019 Diseases and Injuries Collaborators. Global burden of 369 diseases and injuries in 204 countries and territories, 1990-2019: a systematic analysis for the Global Burden of Disease Study 2019. Lancet. 2020 Oct 17;396(10258):1204-1222.

37. Geneen LJ, Martin DJ, Adams N, Clarke C, Dunbar M, Jones D, McNamee P, Schofield P, Smith BH. Effects of education to facilitate knowledge about chronic pain for adults: a systematic review with meta-analysis. Syst Rev. 2015; 4: 132.

38. Haskins R, Rivett DA, Osmotherly PG. Clinical prediction rules in the physiotherapy management of low back pain: a systematic review. Man Ther. 2012 Feb;17(1):9-21. doi: 10.1016/j.math.2011.05.001. Epub 2011 Jun 8. PMID: 21641849.

39. Hayden J, Van Tulder MW, Malmivaara A, et al. Exercise therapy for treatment of non-specific low back pain. Cochrane Database Syst Rev 2005;(3):CD000335.

40. Henderson $\mathrm{CN}$. The basis for spinal manipulation: chiropractic perspective of indications and theory. J Electromyogr Kinesiol. 2012;22:632-642. https://doi.org/10.1016/j. jelekin.2012.03.008 


\section{Referências}

41. Hidalgo B, Detrembleur C, Hall T, Mahaudens P, Nielens H. The efficacy of manual therapy and exercise for different stages of non-specific low back pain: an update of systematic reviews. J Man Manip Ther. 2014; 22(2):59-74.

42. Hoy D, Bain C, Williams G, March L, Brooks P, Blyth F, et al. A systematic review of the global prevalence of low back pain. Arthritis Rheum. 2012; 64(6):2028-37. https://doi.org/10.1002/art.34347.

43. Hoy D, March L, Brooks P, Blyth F, Woolf A, Bain C, et al. The global burden of low back pain: estimates from the global burden of disease 2010 study. Ann Rheum Dis. 2014;73(6):968-74. https://doi.org/10.1136/annrheumdis-2013-204428.

44. Jensen MP, Turner JA, Romano JM, Lawler BK. Relationship of pain-specific beliefs to chronic pain adjustment. Pain. 1994;57(3):301-9.

45. Kamonseki DH, Christenson P, Rezvanifar SC, Calixtre LB. Effects of manual therapy on fear avoidance, kinesiophobia and pain catastrophizing in individuals with chronic musculoskeletal pain: Systematic review and meta-analysis. Musculoskelet Sci Pract. 2021 Feb;51:102311. doi: 10.1016/j.msksp.2020.102311. Epub 2020 Nov 27. PMID: 33302214.

46. Kamper SJ, Apeldoorn AT, Chiarotto A, Smeets RJ, Ostelo RWJG, Guzman J, van Tulder MW. Multidisciplinary biopsychosocial rehabilitation for chronic low back pain. Cochrane Database of Systematic Reviews 2014, Issue 9. Art. No.: CD000963. DOI: 10.1002/14651858.CD000963.pub3.

47. Kamper, Steven J et al. "Global rating of change scales: a review of strengths and weaknesses and considerations for design." The Journal of manual \& manipulative therapy vol. 17,3 (2009): 163-70. doi:10.1179/jmt.2009.17.3.163

48. Klenerman L, Slade PD, Stanley IM, Pennie B, Reilly JP, Atchison LE, Troup JD, Rose MJ. The prediction of chronicity in patients with an acute attack of low back pain in a general practice setting. Spine (Phila Pa 1976). 1995 Feb 15;20(4):478-84. doi: 10.1097/00007632-199502001-00012. PMID: 7747233.

49. Kochhann R, Santos VJ, Macedo LCS, Chaves MLF. 2010. The Mini Mental State Examination: Review of cutoff points adjusted for schooling in a large Southern Brazilian sample. Dementia e Neuropsychologia. 4: 35-41.

50. Koes BW, van Tulder MW, Thomas S. Diagnosis and treatment of low back pain. BMJ. 2006;332(7555):1430-4. https://doi.org/10.1136/bmj.332.7555.1430. 


\section{Referências}

51. Lascurain-Aguirrebeña I, Newham D, Critchley DJ. Mechanism of Action of Spinal Mobilizations: A Systematic Review. Spine (Phila Pa 1976). 2016 Jan;41(2):159-72. doi: 10.1097/BRS.0000000000001151. PMID: 26751060.

52. Lin I, Wiles L, Waller R, Goucke R, Nagree Y, Gibberd M, Straker L, Maher CG, O'Sullivan PPB. What does best practice care for musculoskeletal pain look like? Eleven consistent recommendations from high-quality clinical practice guidelines: systematic review. Br J Sports Med. 2020 Jan;54(2):79-86. doi: 10.1136/bjsports2018-099878. Epub 2019 Mar 2. PMID: 30826805.

53. Louw A, Farrell K, Landers M, et al. The effect of manual therapy and neuroplasticity education on chronic low back pain: a randomized clinical trial. J Man Manip Ther. 2017;25(5):227-234. doi:10.1080/10669817.2016.1231860

54. Louw A, Puentedura EJ, Diener I, Zimney KJ, Cox T. Pain neuroscience education: Which pain neuroscience education metaphor worked best? S Afr J Physiother. 2019 Aug 13;75(1):1329. doi: 10.4102/sajp.v75i1.1329. PMID: 31535053; PMCID: PMC6739553.

55. Mafi JN, McCarthy EP, Davis RB, Landon BE. Worsening trends in the management and treatment of back pain. JAMA Intern Med. 2013;173(17): 1573-81. https://doi.org/10.1001/jamainternmed.2013.8992.

56. Maher C, Underwood M, Buchbinder R. Non-specific low back pain. Lancet. 2016, 10. pii: S0140-6736(16)30970-9.

57. Maitland GD. Maitland Manipulação Vertebral. 7a ed. Rio de Janeiro: Elsevier; 2007.

58. Maughan EF, Lewis JS. Outcome measures in chronic low back pain. Eur Spine J 2010; 19: 1484-94.

59. McGinn TG, Guyatt GH, Wyer PC, Naylor CD, Stiell IG, Richardson WS. Users' guides to the medical literature: XXII: how to use articles about clinical decision rules. Evidence-Based Medicine Working Group. JAMA. 2000 Jul 5;284(1):79-84. doi: 10.1001/jama.284.1.79. PMID: 10872017. Laupacis A, Sekar N, Stiell IG. Clinical prediction rules: a review and suggested mod- ifications of methodological standards. JAMA. 1997;277:488 - 494.

60. Meier ML, Hotz-Boendermaker S, Boendermaker B, Luechinger R, Humphreys BK. Neural responses of posterior to anterior movement on lumbar vertebrae: a functional 
magnetic resonance imaging study. J Manipulative Physiol Ther. 2014;37:32-41. https://doi.org/10.1016/j. jmpt.2013.09.004

61. Mellin G. Correlation of hip mobility with degree of back pain and lumbar spinal mobility in chronic low back pain patients. Spine 1988;13:668 -70.

62. Menke JM. Do manual therapies help low back pain? A comparative effectiveness meta-analysis. Spine J 2014;39:E463-72.

63. Millan M, Leboeuf-Yde C, Budgell B, Amorim MA. The effect of spinal manipulative therapy on experimentally induced pain: a systematic literature review. Chiropr Man Therap. 2012;20:26.

64. Moher D, Hopewell S, Schulz KF, et al. CONSORT 2010 Explanation and Elaboration: updated guidelines for reporting parallel group randomised trials. BMJ. 2010;340(mar23 1):c869-c869.

65. Monticone M, Frigau L, Vernon H, Rocca B, Giordano A, Vullo SS, Mola F, Franchignoni F. Reliability, responsiveness and minimal clinically important difference of the two Fear Avoidance and Beliefs Questionnaire scales in Italian subjects with chronic low back pain undergoing multidisciplinary rehabilitation. Eur J Phys Rehabil Med. 2020

66. Monticone M, Portoghese I, Rocca B, Giordano A, Campagna M, Franchignoni F. Responsiveness and minimal important change of the Pain Catastrophizing Scale in people with chronic low back pain undergoing multidisciplinary rehabilitation. Eur J Phys Rehabil Med 2021 May 27. DOI: 10.23736/S1973-9087.21.06729-0

67. Moseley AM, Herbert RD, Sherrington C, Maher CG. Evidence for physiotherapy practice: a survey of the Physiotherapy Evidence Database (PEDro). Aust J Physiother. 2002;48(1):43-49.

68. Moseley GL, Butler DS. Fifteen Years of Explaining Pain: The Past, Present, and Future. J Pain. 2015;16(9):807-813.

69. Moseley GL, Vlaeyen JW. Beyond nociception: The imprecision hypothesis of chronic pain. Pain. 2015;156(1):35-38.

70. Murray CJ, Atkinson C, Bhalla K, et al. The state of US health, 1990-2010: burden of diseases, injuries, and risk factors. JAMA 2013; 310: 591-608.

71. National Institute for Health and Care Excellence. Chronic pain (primary and secondary) in over 16s: assessment of all chronic pain and management of chronic primary pain. NG193. April 7, 2021. https://www. nice.org.uk/guidance/ng193 


\section{Referências}

72. National Institute for Health and Care Excellence. Low back pain and sciatica in over 16s: assessment and management (NICE Guideline NG59). 2016. www.nice.org.uk/guidance/ng59

73. O'Keeffe M, Purtill H, Kennedy N, O'Sullivan P, Dankaerts W, Tighe A, Allworthy L, Dolan L, Bargary N, O'Sullivan K. Individualised cognitive functional therapy compared with a combined exercise and pain education class for patients with nonspecific chronic low back pain: study protocol for a multicentre randomised controlled trial. BMJ Open. 2015; 5(6): e007156.

74. Ogura T, Tashiro M, Masud M, et al. Cerebral metabolic changes in men after chiropractic spinal manipulation for neck pain. Altern Ther Health Med. 2011;17:1217.

75. Ostelo RWJG, Deyo RA, Stratford P, et al. Interpreting Change Scores for Pain and Functional Status in Low Back Pain. Spine (Phila Pa 1976). 2008;33(1):90-94.

76. Pais-Ribeiro J, Silva I, Ferreira T, Martins A, Meneses R, Baltar M. Validation study of a Portuguese version of the hospital Anxiety and Depression scale. Psychol Health Med 2007;12:225-237.

77. Petrozzi MJ, Leaver A, Ferreira PH, Rubinstein SM, Jones MK, Mackey MG. Addition of MoodGYM to physical treatments for chronic low back pain: A randomized controlled trial. Chiropr Man Therap. 2019 Oct 25;27:54. doi: 10.1186/s12998-019-0277-4. PMID: 31673330; PMCID: PMC6814139.

78. Pilz B, Vasconcelos RA, Marcondes FB, Lodovichi SS, Mello W, Grossi DB. The Brazilian version of STarT Back Screening Tool - translation, cross-cultural adaptation and reliability. Braz J Phys Ther. 2014;18(5):453-61.

79. Pilz B, Vasconcelos RA, Teixeira PP, Mello W, Marcondes FB, Hill JC, Grossi DB. Construct and discriminant validity of STarT Back Screening Tool - Brazilian version. Braz J Phys Ther. 2017; 21(1):69-73.

80. Puentedura EJ, Flynn T. Combining manual therapy with pain neuroscience education in the treatment of chronic low back pain: A narrative review of the literature. Physiother Theory Pract. 2016;32(5):408-414.

81. Raja SN, Carr DB, Cohen M, Finnerup NB, Flor H, Gibson S, Keefe FJ, Mogil JS, Ringkamp M, Sluka KA, Song XJ, Stevens B, Sullivan MD, Tutelman PR, Ushida T, Vader K. The revised International Association for the Study of Pain definition of pain: concepts, challenges, and compromises. Pain. 2020 Sep 1;161(9):1976-1982. 


\section{Referências}

82. Rajaee SS, Bae HW, Kanim LEA, Delamarter RB. Spinal fusion in the United States: analysis of trends from 1998 to 2008. Spine. 2012;37(1):67-76. https://doi.org/10.1097/BRS.0b013e31820cccfb.

83. Rhon DI, Deyle GD. Manual Therapy: Always a Passive Treatment? J Orthop Sports Phys Ther. 2021 Jul 1:1-11.

84. Rubinstein SM, de Zoete A, van Middelkoop M, Assendelft WJJ, de Boer MR, van Tulder MW. Benefits and harms of spinal manipulative therapy for the treatment of chronic low back pain: systematic review and meta-analysis of randomised controlled trials. BMJ. 2019 Mar 13;364:1689. doi: 10.1136/bmj.1689. PMID: 30867144; PMCID: PMC6396088.

85. Rubinstein SM, van Eekelen R, Oosterhuis T, de Boer MR, Ostelo RW, van Tulder MW. The risk of bias and sample size of trials of spinal manipulative therapy for low back and neck pain: analysis and recommendations. J Manipulative Physiol Ther. 2014;37(8):523-541. doi:10.1016/j.jmpt.2014.07.007

86. Saracoglu I, Arik MI, Afsar E, Gokpinar HH. The effectiveness of pain neuroscience education combined with manual therapy and home exercise for chronic low back pain: A single-blind randomized controlled trial. Physiother Theory Pract. 2020 Aug 19:1-11.

87. Sarda J, Nicholas MK, Pimenta CAM, Asghari A: Pain-related self-efficacy beliefs in a Brazilian chronic pain patient sample: A psychometric analysis. Stress Health 23: 185-190, 2007.

88. Schmidt I, Rechter L, Hansen VK, Andreasen J, Overvad K. Prognosis of subacute low back pain patients according to pain response. Eur Spine J. 2008 Jan;17(1):5763. doi: 10.1007/s00586-007-0436-5. Epub 2007 Sep 5. PMID: 17805584; PMCID: PMC2365517.

89. Seabra MLV, Concilio G, Villares JB, Carlini EA. Avaliação do teste "Mini-mental state" em voluntários e pacientes brasileiros. Rev Bras Psiquiatr 1990; 12(1/4):1-29.

90. Sehn F, Chachamovich E, Vidor LP, et al. Cross-Cultural Adaptation and Validation of the Brazilian Portuguese Version of the Pain Catastrophizing Scale. Pain Med. 2012;13(11):1425-1435.

91. Sparks C, Cleland JA, Elliott JM, Zagardo M, Liu WC. Using functional magnetic resonance imaging to determine if cerebral hemodynamic responses to pain change 


\section{Referências}

following thoracic spine thrust manipulation in healthy individuals. J Orthop Sports Phys Ther. 2013;43:340-348. https://doi.org/10.2519/jospt.2013.4631

92. Stanton TR, Hancock MJ, Maher CG, Koes BW. Critical appraisal of clinical prediction rules that aim to optimize treatment selection for musculoskeletal conditions. Phys Ther. 2010 Jun;90(6):843-54. doi: 10.2522/ptj.20090233. Epub 2010 Apr 22. PMID: 20413577.

93. Vigatto R, Alexandre NMC, Correa HR. Development of a Brazilian Portuguese Version of the Oswestry Disability Index. Spine (Phila Pa 1976) 2007; 32: 481-486.

94. Wang X-Q, Zheng J-J, Yu Z-W, et al. A meta-analysis of core stability exercise versus general exercise for chronic low back pain. PLoS ONE 2012;7:e52082.

95. Watson JA et al. Pain Neuroscience Education for Adults With Chronic Musculoskeletal Pain: A Mixed-Methods Systematic Review and Meta-Analysis. J Pain. 2019

96. Wertli MM, Eugster R, Held U, Steurer J, Kofmehl R, Weiser S. Catastrophizing-a prognostic factor for outcome in patients with low back pain: a systematic review. Spine J 2014; 14:2639-57.

97. Wertli MM, Rasmussen-Barr E, Held U, Weiser S, Bachmann LM, Brunner F. Fearavoidance beliefs-a moderator of treatment efficacy in patients with low back pain: a systematic review. Spine J 2014; 14:2658-78.

98. Wong JJ, Côté P, Sutton DA, Randhawa K, Yu H, Varatharajan S, Goldgrub R, Nordin M, Gross DP, Shearer HM, Carroll LJ, Stern PJ, Ameis A, Southerst D, Mior S, Stupar M, Varatharajan T, Taylor-Vaisey A. Clinical practice guidelines for the noninvasive management of low back pain: A systematic review by the Ontario Protocol for Traffic Injury Management (OPTIMa) Collaboration. Eur J Pain. 2017 Feb;21(2):201-216. doi: 10.1002/ejp.931. Epub 2016 Oct 6. PMID: 27712027.

99. Wood L, Hendrick PA. A systematic review and meta-analysis of pain neuroscience education for chronic low back pain: Short-and long-term outcomes of pain and disability. Eur J Pain. 2019 Feb;23(2):234-249. 


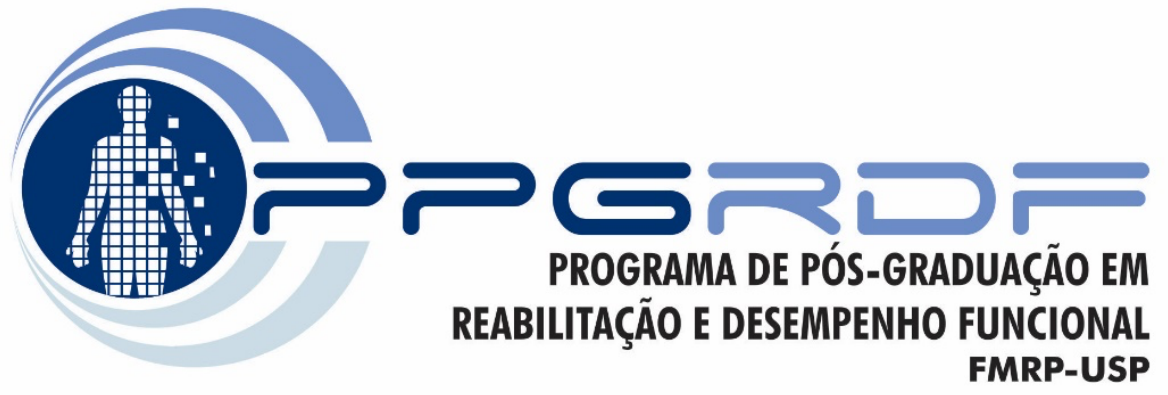

\section{ANEXOS}

$\mathbf{E}$

"O caminho mais certo de vencer é tentar mais

uma vez."

Thomas Edison

Albert Einstein 


\title{
APÊNDICE A - Termo de Consentimento Livre e Esclarecido
}

\author{
Pesquisadores Responsáveis \\ Profa. Dra. Thaís Cristina Chaves | (chavestc@fmrp.usp.br) (016) 3602.4694 \\ Fernando Augusto Gonçalves Tavares | (drfernando@institutoa.com.br) Fone: (17) 98122.9897
}

Título da Pesquisa - Efeito Adicional da Educação em Neurociência sobre a Dor em Pacientes com
Dor Lombar Crônica Classificados no Subgrupo de Terapia Manual: Ensaio Clínico Aleatorizado
Cego

O(a) senhor(a) está sendo convidado para participar desta pesquisa, cujo objetivo será verificar o verificar o efeito adicional da Educação sobre Neurociência da dor em relação a Terapia Manual nos desfechos primários intensidade de dor e incapacidade em pacientes com dor lombar crônica não específica.

Em uma primeira etapa, o(a) senhor(a) responderá a algumas questões sobre seu estado emocional e dificuldades relacionadas a sua dor na coluna. Posteriormente, o(a) senhor(a) será convidado a receber um tratamento chamado Terapia Manual em que as vértebras da coluna são minimamente movimentadas para diminuição da dor e incapacidade. Poderão também ser ministradas orientações sobre dor e como esses aspectos influencinam os pensamentos e emoções.

Depois deste período o(a) senhor(a) será re-avaliado da mesma forma como ocorreu na avaliação inicial. Todas as avaliações ocorrerão no Núcleo Integrado de Reabilitação - NIR de São José do Rio Preto. Cada avaliação terá a duração de 1 hora.

Ao participar desta pesquisa o(a) senhor(a) terá o benefício direto de receber um tratamento inovador sua dor na coluna e sem efeitos colaterais. Um dos grupos (que será formado por sorteio) deste estudo receberá apenas o tratamento de mobilização articular e o outro receberá além das intervenções, orientações gerais sobre educação em neurociências da dor.

Existe um risco mínimo nessa pesquisa relacionado ao sigilo de identidade, entretanto todas as informações colhidas serão mantidas em sigilo, assim como a identidade do (a) senhor(a) através da adoção de senhas em arquivos e numeração dos dados nas planilhas. Não existe nenhum tipo de seguro de saúde ou de vida que possa beneficiar em função da participação do (a) senhor (a) neste estudo. Não há quaisquer relatos na literatura sobre efeitos adversos relacionados a mobilização articular. A participação do (a) senhor(a) neste estudo depende plenamente da sua autorização. É direito do (a) senhor (a) deixar de participar deste estudo em qualquer momento sem que isso gere prejuízo ao senhor (a). Também não haverá gasto adicional devido à participação neste projeto.

As informações obtidas nesta pesquisa não serão de maneira alguma associadas à identidade do (a) senhor(a) e não poderão ser consultadas por quaisquer outras pessoas leigas sem autorização oficial. Estas informações poderão ser utilizadas para fins científicos, desde que fiquem resguardadas a privacidade e anonimato dos participantes da pesquisa.

O senhor(a) tem todo direito de procurar o pesquisador responsável para solucionar dúvidas e obter informações, antes, durante ou mesmo após o curso da pesquisa. Eventuais dúvidas sobre os aspectos éticos relacionados a essa pesquisa podem ser esclarecidas junto ao Comitê de Ética do Centro Saúde Escola Cuiabá da Faculdade de Medicina de Ribeirão Preto pelo qual este projeto foi aprovado. (16) 3315-0009 $\mathrm{O}(\mathrm{A})$ senhor (a) foi informado (a) através dos responsáveis pelo estudo sobre todos os riscos envolvidos, a importância da pesquisa e as eventuais dúvidas sobre a pesquisa em questão serão prontamente respondidas. É direito do participante manter uma via deste consentimento.

Assinatura do voluntário:

Nome do voluntário:

RG: $\quad$ Data de nascimento:

Assinatura do pesquisador responsável:

Nome do pesquisador:

RG: 
Ribeirão Preto, de de 20 
ANEXO A - Documento de aprovação do projeto

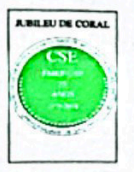

\section{CENTRO DE SAÚDE ESCOLA \\ FACULDADE DE MEDICINA DE RIBEIRÃO PRETO \\ UNIVERSIDADE DE SÃO PAULO}

OF. 022/2017-CEP/CSE-FMRP-USP

Ribeirão Preto, 01 de Agosto de 2017.

Prezada Senhora

Comunicamos que o projeto de pesquisa abaixo especificado foi analisado e APROVADO pelo Comitê de Ética em pesquisa do Centro de Saúde Escola da Faculdade de Medicina de Ribeirão Preto da Universidade de São Paulo, na data de 01 de Agosto de 2017.

CAAE: 69387916.7 .0000 .5414

Projeto de pesquisa: "Efeito adicional da educação em neurociência sobre a dor em pacientes com dor lombar crônica classificados no subgrupo de terapia manual: ensaio clínico aleatorizado cego

Em atendimento à Resolução 466/12, deverá ser encaminhado a este CEP o relatório final da pesquisa e a publicação de seus resultados, para acompanhamento, bem como comunicada qualquer intercorrência ou a sua interrupção.

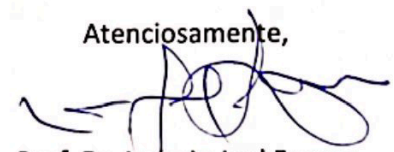

Prof. Dr. Laercio Joel Franco

Coordenador do CEP/CSE-FMRP-USP

Ilma. Profa. Dra. Thais Cristina Chaves

Docente do Departamento de Neurociências e Ciências do Comportamento da Faculdade de Medicina de Ribeirão Preto/USP

RUA TEREZINA, NN 690 - SUMAREZINHO - CEP 14055-380 - RIBEIRÃO PRETO - SP FONE: (16) 3315-0000/0001FAX: (16) 3315-0029 EMAIL: CSECUIABA@FMRP.USP.BR 
ANEXO A - Mini Exame do Estado Mental

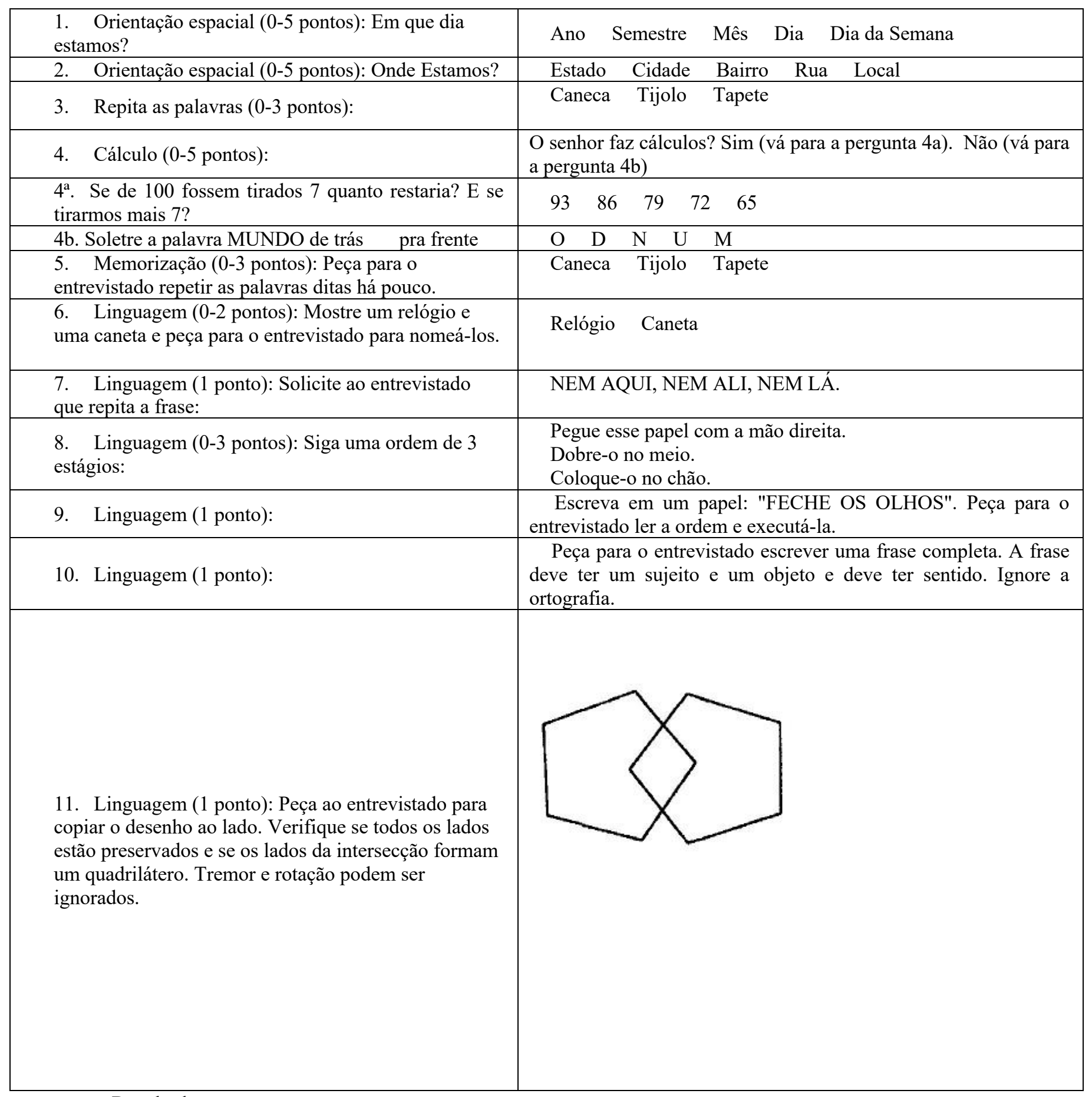

Resultado:

Normal: acima de 27 pontos

Demência: menor ou igual a 24 pontos; em caso de menos de 4 anos de escolaridade, o ponto de corte passa para 17 , em vez de 24 
ANEXO B - Escala Numérica de Dor

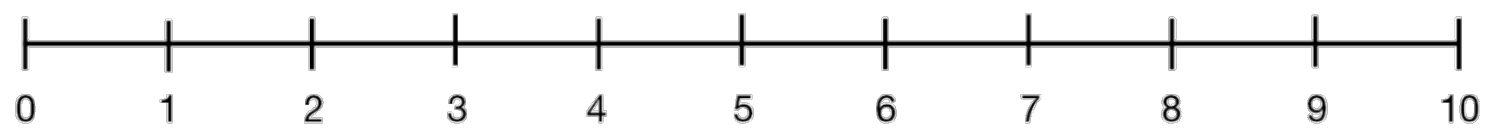

Sem dor

Pior dor possível 
ANEXO C - Índice de Incapacidade Lombar Oswestry (ODI)

Por favor, responda esse questionário. Ele foi desenvolvido para dar-nos informações sobre como seu problema nas costas tem afetado a sua capacidade de realizar as atividades da vida diária. Por favor, responda a todas as seções. Assinale em cada uma delas apenas a resposta que mais claramente descreve a sua condição no dia de hoje.

Seção 1 - Intensidade da Dor

( ) Não sinto dor no momento.

( ) A dor é muito leve no momento.

( ) A dor é moderada no momento.

( ) A dor é razoavelmente intensa no momento.

( ) A dor é muito intensa no momento.

( ) A dor é a pior que se pode imaginar no momento.

Seção 2 - Cuidados Pessoais (lavar-se, vestir-se, etc.)

( ) Posso cuidar de mim mesmo normalmente sem que isso aumente a dor.

( ) Posso cuidar de mim mesmo normalmente, mas sinto muita dor.

( ) Sinto dor ao cuidar de mim mesmo e faço isso lentamente e com cuidado.

( ) Necessito de alguma ajuda, porém consigo fazer a maior parte dos meus cuidados pessoais.

( ) Necessito de ajuda diária na maioria dos aspectos de meus cuidados pessoais.

( ) Não consigo me vestir, lavo-me com dificuldade e permaneço na cama.

Seção 3 - Levantar Objetos

( ) Consigo levantar objetos pesados sem aumentar a dor.

( ) Consigo levantar objetos pesados, mas isso aumenta a dor.

( ) A dor me impede de levantar objetos pesados do chão, mas consigo levantá-los se estiverem convenientemente posicionados, por exemplo, sobre uma mesa.

( ) A dor me impede de levantar objetos pesados, mas consigo levantar objetos leves a moderados, se estiverem convenientemente posicionados.

( ) Consigo levantar apenas objetos muito leves.

( ) Não consigo levantar ou carregar absolutamente nada.

Seção 4 - Caminhar

( ) A dor não me impede de caminhar qualquer distância.

( ) A dor me impede de caminhar mais de 1.600 metros (aproximadamente 16 quarteirões de 100 metros).

( ) A dor me impede de caminhar mais de 800 metros (aproximadamente 8 quarteirões de 100 metros).

( ) A dor me impede de caminhar mais de 400 metros (aproximadamente 4 quarteirões de 100 metros).

( ) Só consigo andar usando uma bengala ou muletas.

( ) Fico na cama a maior parte do tempo e preciso me arrastar para ir ao banheiro.

Seção 5 - Sentar

( ) Consigo sentar em qualquer tipo de cadeira durante o tempo que quiser.

( ) Consigo sentar em uma cadeira confortável durante o tempo que quiser.

( ) A dor me impede de ficar sentado por mais de 1 hora.

( ) A dor me impede de ficar sentado por mais de meia hora.

( ) A dor me impede de ficar sentado por mais de 10 minutos.

( ) A dor me impede de sentar.

Seção 6 - Ficar em Pé

( ) Consigo ficar em pé o tempo que quiser sem aumentar a dor.

( ) Consigo ficar em pé durante o tempo que quiser, mas isso aumenta a dor.

( ) A dor me impede de ficar em pé por mais de 1 hora.

( ) A dor me impede de ficar em pé por mais de meia hora.

( ) A dor me impede de ficar em pé por mais de 10 minutos.

( ) A dor me impede de ficar em pé.

Seção 7 - Dormir

( ) Meu sono nunca é perturbado pela dor.

( ) Meu sono é ocasionalmente perturbado pela dor.

( ) Durmo menos de 6 horas por causa da dor.

( ) Durmo menos de 4 horas por causa da dor. 
( ) Durmo menos de 2 horas por causa da dor.

( ) A dor me impede totalmente de dormir.

Seção 8 - Vida Sexual

( ) Minha vida sexual é normal e não aumenta minha dor.

( ) Minha vida sexual é normal, mas causa um pouco mais de dor.

( ) Minha vida sexual é quase normal, mas causa muita dor.

( ) Minha vida sexual é severamente limitada pela dor.

( ) Minha vida sexual é quase ausente por causa da dor.

( ) A dor me impede de ter uma vida sexual.

\section{Seção 9 - Vida Social}

( ) Minha vida social é normal e não aumenta a dor.

( ) Minha vida social é normal, mas aumenta a dor.

( ) A dor não tem nenhum efeito significativo na minha vida social, porém limita alguns interesses que demandam mais energia, como por exemplo, esporte, etc.

( ) A dor tem restringido minha vida social e não saio de casa com tanta freqüência.

( ) A dor tem restringido minha vida social ao meu lar.

( ) Não tenho vida social por causa da dor.

Seção 10 - Locomoção (ônibus/carro/táxi)

( ) Posso ir a qualquer lugar sem sentir dor.

( ) Posso ir a qualquer lugar, mas isso aumenta a dor.

( ) A dor é intensa, mas consigo me locomover durante 2 horas.

( ) A dor restringe-me a locomoções de menos de 1 hora.

( ) A dor restringe-me a pequenas locomoções necessárias de menos de 30 minutos.

( ) A dor impede de locomover-me, exceto para receber tratamento. 
ANEXO D - Fear Avoidance Beliefs Questionnaire (FABQ-Brasil)

Opções de resposta

\begin{tabular}{|c|c|c|c|c|c|c|}
\hline $\begin{array}{c}\text { Discordo } \\
\text { completamente } \\
0\end{array}$ & $\begin{array}{c}\text { Discordo } \\
\text { razoavelmente }\end{array}$ & $\begin{array}{c}\text { Discordo } \\
\text { ligeiramente }\end{array}$ & $\begin{array}{c}\text { Não sei dizer } \\
\mathbf{1}\end{array}$ & $\begin{array}{c}\text { Concordo } \\
\text { ligeiramente }\end{array}$ & $\begin{array}{c}\text { Concordo } \\
\text { razoavelmente } \\
5\end{array}$ & $\begin{array}{c}\text { Concordo } \\
\text { completamente } \\
6\end{array}$ \\
\hline
\end{tabular}

Para cada afirmação, favor circular um número de 0 a 6 , para informar quanto às atividades físicas como fletir o tronco, levantar, caminhar ou dirigir, afetam ou afetariam sua dor nas costas.

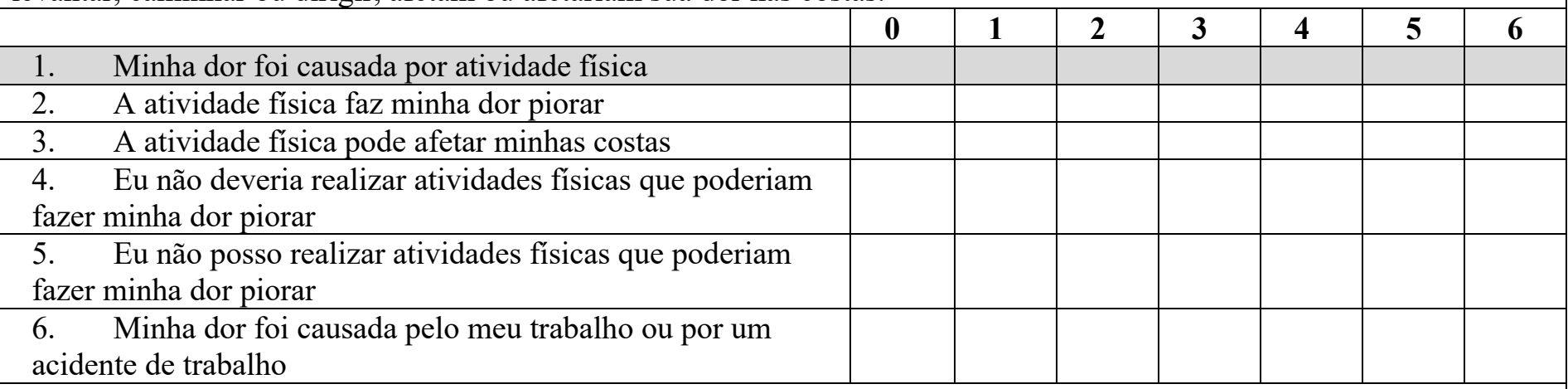

Para cada afirmação, favor circular um número de 0 a 6, para informar quanto o seu trabalho normal afeta ou afetaria sua dor nas costas.

7. Meu trabalho agravou minha dor

8. Eu tenho uma reivindicação de pensão em virtude da minha dor

9. Meu trabalho é muito pesado para mim

10. Meu trabalho faz ou poderia fazer minha dor piorar

11. Meu trabalho pode prejudicar minhas costas

12. Eu não deviria realizar meu trabalho normal com minha dor atual

13. Eu não posso realizar meu trabalho normal com minha dor atual

14. Eu não posso realizar meu trabalho normal até que minha dor seja tratada

15. Eu não acho que estarei de volta ao trabalho normal dentro de três meses

16. Eu não acho que algum dia eu estarei apto para retornar ao meu trabalho

FABQ Phys (0-24) - P>15= indicador forte para crença de medo e evitação de atividades físicas

FABQ Work (0-42) - P >34 = indicador forte para crença de medo e evitação de atividades laborais 


\section{ANEXO E - Escala de Autoeficácia Sobre Dor (PESE)}

Por favor, indique o quanto confiante você está neste momento em poder fazer as seguintes coisas apesar da sua dor. Para indicar sua resposta, circule um número em cada questão, considerando que (0) indica nem um pouco confiante e (6) completamente confiante.

Por exemplo:

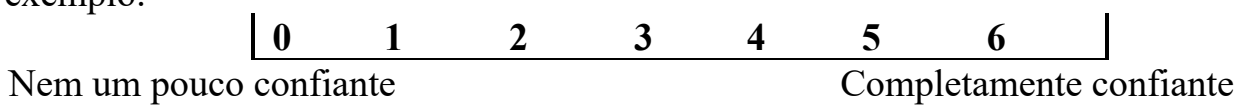

Lembre-se, este questionário não está perguntando se você tem feito estas coisas ou não. Mas sim o quanto confiante você se sente em poder fazê-las neste momento, apesar da sua dor.

1. Posso aproveitar as coisas apesar da dor.

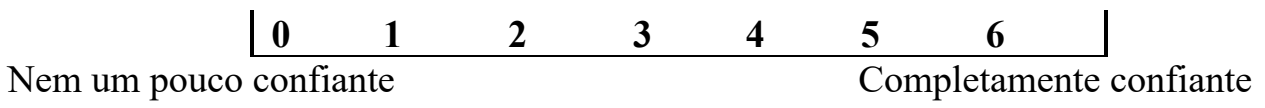

2. Posso fazer a maior parte das minhas tarefas domésticas (ex: Lavar a louca, arrumar a casa, lavar o carro....) apesar da dor.

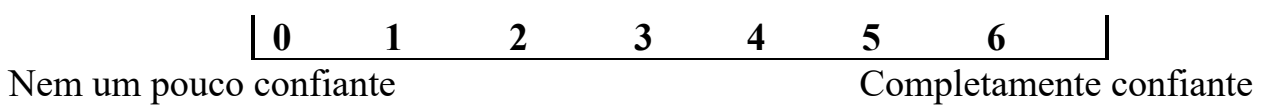

3. Continuo encontrando meus amigos e familiares com a mesma frequência que antes apesar da dor.

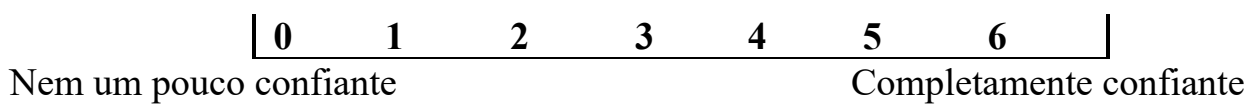

4. Posso lidar com a dor na maior parte das situações.

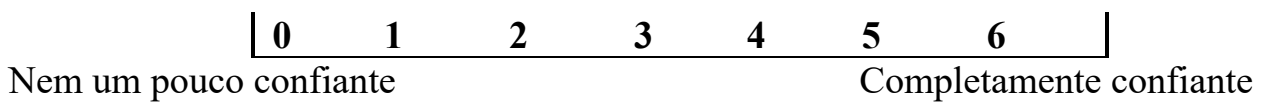

5. Posso fazer alguns trabalhos apesar da minha dor (ex: trabalhos de casa e emprego remunerado ou não).

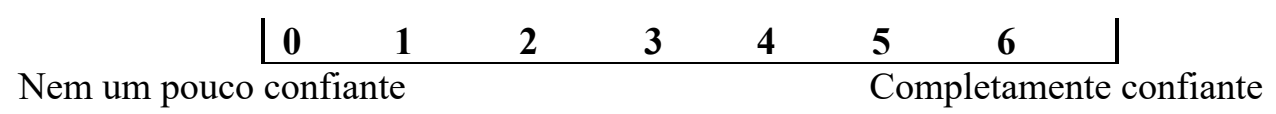

6. Posso fazer muitas coisas que aprecio apesar da dor (ex: lazer, artesanato, esporte.....).

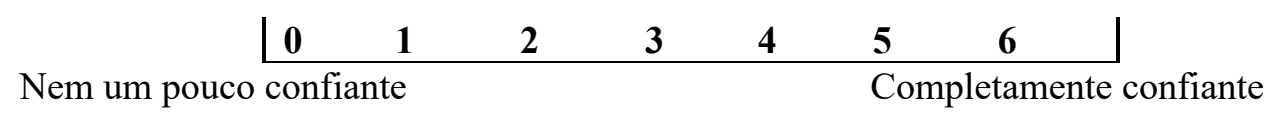

7. Posso lidar com a dor sem usar remédios.

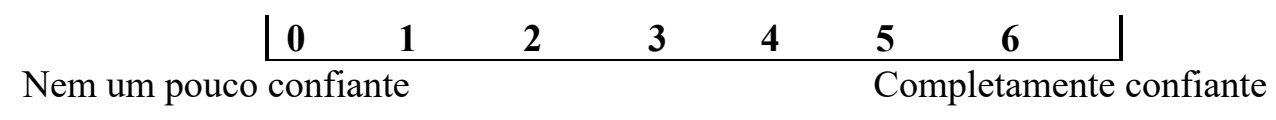


8. Posso alcançar a maior parte dos meus objetivos na vida apesar da dor.

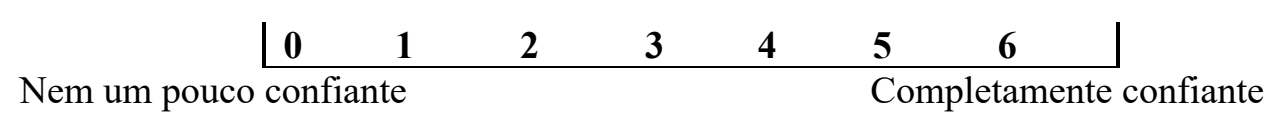

9. Apesar da dor posso viver uma vida normal.

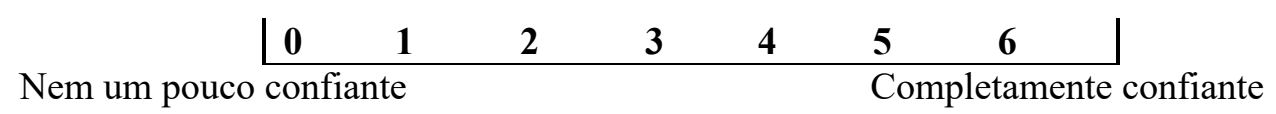

10. Posso aos poucos me tornar mais ativo apesar da dor.

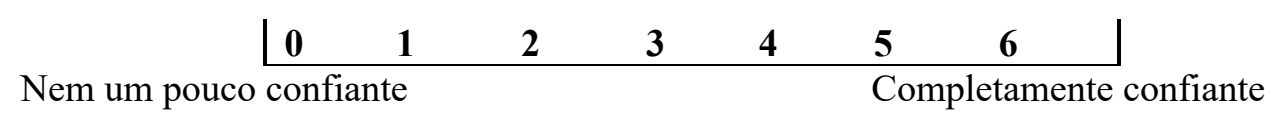


ANEXO F - Escala de Percepção Global da Efeito (GPE)

Comparado a quando este episódio de dor lombar começou, como você descreveria sua dor lombar nos últimos dias?

\begin{tabular}{|c|c|c|c|c|c|c|c|c|c|c|}
\hline-5 & -4 & -3 & -2 & -1 & 0 & 1 & 2 & 3 & 4 & 5 \\
\hline
\end{tabular}
$\begin{aligned} & \text { Extremamente } \\
& \text { pior }\end{aligned}$
$\begin{gathered}\text { Sem } \\
\text { modificação }\end{gathered}$

\begin{tabular}{|l|l|}
\hline Escalas & Pós \\
\hline Percepção & \\
\hline
\end{tabular}


ANEXO G - StarT Back Screening Tool (SBST Brasil)

\begin{tabular}{|l|l|l|}
\hline Questões StarT Back Screening Tool & Discordo - 0 & Concordo - 1 \\
\hline 1. A minha dor nas costas se espalhou pelas pernas nas duas últimas semanas & & \\
\hline $\begin{array}{l}\text { 2. Eu tive dor no ombro e/ou na nuca pelo menos uma vez nas últimas duas } \\
\text { semanas }\end{array}$ & & \\
\hline $\begin{array}{l}\text { 3. Eu evito andar longas distâncias por causa da minha dor nas costas } \\
\text { 4. Nas duas últimas semanas, tenho me vestido mais devagar por causa da } \\
\text { minha dor nas costas }\end{array}$ & & \\
\hline $\begin{array}{l}\text { 5. A atividade física não é realmente segura para uma pessoa com um problema } \\
\text { como o meu }\end{array}$ & & \\
\hline 6. Tenho ficado preocupado por muito tempo por causa da minha dor nas costas & & \\
\hline 7. Eu sinto que minha dor nas costas é terrível e que nunca vai melhorar & & \\
\hline 8. Em geral, eu não tenho gostado de todas as coisas como eu costumava gostar & & \\
\hline $\begin{array}{l}\text { 9. Em geral, quanto a sua dor nas costas te incomodou nas duas ultimas semanas } \\
\text { ( ) Nada - 0 ( ) Pouco -0 ( ) Moderado - 0 ( ) Muito - 1 Extremamente - 1 ( ) }\end{array}$ & & \\
\hline
\end{tabular}

Pontuação total (9 itens):

Subescala psicossocial (5-9 itens): 
ANEXO H - Escala de Pensamentos Catastróficos Sobre a Dor (PCS)

Instruções: Listamos 13 declarações que descrevem diferentes pensamentos e sentimentos que podem lhe aparecer na cabeça quando sente dor. Indique o grau destes pensamentos e sentimentos quando está com dor.

\begin{tabular}{|c|c|c|c|c|c|}
\hline & $\begin{array}{l}\text { Mínima } \\
0\end{array}$ & $\begin{array}{c}\text { Leve } \\
1\end{array}$ & $\begin{array}{l}\text { Moderada } \\
\quad 2\end{array}$ & $\begin{array}{c}\text { Intensa } \\
3\end{array}$ & $\begin{array}{l}\text { Muito intensa } \\
\quad 4\end{array}$ \\
\hline $\begin{array}{l}\text { 1. A preocupação durante todo o tempo } \\
\text { com a duração da dor é }\end{array}$ & $\begin{array}{l}\text { Mínimo } \\
0\end{array}$ & $\begin{array}{c}\text { Leve } \\
1\end{array}$ & $\begin{array}{l}\text { Moderada } \\
\quad 2\end{array}$ & $\begin{array}{c}\text { Intensa } \\
\quad 3\end{array}$ & $\begin{array}{l}\text { Muito intensa } \\
\quad 4\end{array}$ \\
\hline $\begin{array}{l}\text { 2. O sentimento de não poder prosseguir } \\
\text { (continuar) é }\end{array}$ & $\begin{array}{l}\text { Mínimo } \\
0\end{array}$ & $\begin{array}{c}\text { Leve } \\
1\end{array}$ & $\begin{array}{l}\text { Moderada } \\
\quad 2\end{array}$ & $\begin{array}{c}\text { Intensa } \\
\quad 3\end{array}$ & $\begin{array}{l}\text { Muito intensa } \\
\quad 4\end{array}$ \\
\hline $\begin{array}{l}\text { 3. O sentimento que a dor é terrível e } \\
\text { não vai melhorar é }\end{array}$ & $\begin{array}{l}\text { Mínimo } \\
0\end{array}$ & $\begin{array}{c}\text { Leve } \\
1\end{array}$ & $\begin{array}{l}\text { Moderada } \\
\quad 2\end{array}$ & $\begin{array}{l}\text { Intensa } \\
\quad 3\end{array}$ & $\begin{array}{l}\text { Muito intensa } \\
\quad 4\end{array}$ \\
\hline $\begin{array}{l}\text { 4. O sentimento que a dor é horrível e } \\
\text { você não vai resistir é }\end{array}$ & $\begin{array}{l}\text { Mínimo } \\
0\end{array}$ & $\begin{array}{c}\text { Leve } \\
1\end{array}$ & $\begin{array}{l}\text { Moderada } \\
\quad 2\end{array}$ & $\begin{array}{l}\text { Intensa } \\
\quad 3\end{array}$ & $\begin{array}{l}\text { Muito intensa } \\
\quad 4\end{array}$ \\
\hline $\begin{array}{l}\text { 5. O pensamento de não poder estar } \\
\text { mais com alguém é }\end{array}$ & $\begin{array}{l}\text { Mínimo } \\
0\end{array}$ & $\begin{array}{c}\text { Leve } \\
1\end{array}$ & $\begin{array}{l}\text { Moderada } \\
\quad 2\end{array}$ & $\begin{array}{c}\text { Intensa } \\
\quad 3\end{array}$ & $\begin{array}{l}\text { Muito intensa } \\
\quad 4\end{array}$ \\
\hline $\begin{array}{l}\text { 6. O medo que a dor pode se tornar } \\
\text { ainda pior é }\end{array}$ & $\begin{array}{l}\text { Mínimo } \\
0\end{array}$ & $\begin{array}{c}\text { Leve } \\
1\end{array}$ & $\begin{array}{l}\text { Moderada } \\
2\end{array}$ & $\begin{array}{c}\text { Intensa } \\
\quad 3\end{array}$ & $\begin{array}{l}\text { Muito intensa } \\
\quad 4\end{array}$ \\
\hline $\begin{array}{l}\text { 7. O pensamento sobre outros episódios } \\
\text { de dor é }\end{array}$ & $\begin{array}{l}\text { Mínimo } \\
0\end{array}$ & $\begin{array}{c}\text { Leve } \\
1\end{array}$ & $\begin{array}{l}\text { Moderada } \\
2\end{array}$ & $\begin{array}{c}\text { Intensa } \\
\quad 3\end{array}$ & $\begin{array}{l}\text { Muito intensa } \\
\quad 4\end{array}$ \\
\hline $\begin{array}{l}\text { 8. O desejo profundo que a dor } \\
\text { desapareça é }\end{array}$ & $\begin{array}{l}\text { Mínimo } \\
0\end{array}$ & $\begin{array}{c}\text { Leve } \\
1\end{array}$ & $\begin{array}{l}\text { Moderada } \\
2\end{array}$ & $\begin{array}{c}\text { Intensa } \\
\quad 3\end{array}$ & $\begin{array}{l}\text { Muito intensa } \\
\quad 4\end{array}$ \\
\hline $\begin{array}{l}\text { 9. O sentimento de não conseguir tirar a } \\
\text { dor do pensamento é }\end{array}$ & $\begin{array}{l}\text { Mínimo } \\
0\end{array}$ & $\begin{array}{c}\text { Leve } \\
1\end{array}$ & $\begin{array}{l}\text { Moderada } \\
\quad 2\end{array}$ & $\begin{array}{c}\text { Intensa } \\
\quad 3\end{array}$ & $\begin{array}{l}\text { Muito intensa } \\
\quad 4\end{array}$ \\
\hline $\begin{array}{l}\text { 10. O pensamento que ainda poderá doer } \\
\text { mais é }\end{array}$ & $\begin{array}{l}\text { Mínimo } \\
0\end{array}$ & $\begin{array}{c}\text { Leve } \\
1\end{array}$ & $\begin{array}{l}\text { Moderada } \\
\quad 2\end{array}$ & $\begin{array}{c}\text { Intensa } \\
\quad 3\end{array}$ & $\begin{array}{l}\text { Muito intensa } \\
\quad 4\end{array}$ \\
\hline $\begin{array}{l}\text { 11. O pensamento que a dor é grave } \\
\text { porque ela não quer parar é }\end{array}$ & $\begin{array}{l}\text { Mínimo } \\
0\end{array}$ & $\begin{array}{c}\text { Leve } \\
1\end{array}$ & $\begin{array}{l}\text { Moderada } \\
\quad 2\end{array}$ & $\begin{array}{c}\text { Intensa } \\
\quad 3\end{array}$ & $\begin{array}{l}\text { Muito intensa } \\
\quad 4\end{array}$ \\
\hline $\begin{array}{l}\text { 12. O pensamento de que não há nada } \\
\text { para fazer para diminuir a intensidade } \\
\text { da dor é }\end{array}$ & $\begin{array}{l}\text { Mínimo } \\
0\end{array}$ & $\begin{array}{l}\text { Leve } \\
1\end{array}$ & $\begin{array}{l}\text { Moderada } \\
\quad 2\end{array}$ & $\begin{array}{c}\text { Intensa } \\
3\end{array}$ & $\begin{array}{l}\text { Muito intensa } \\
\quad 4\end{array}$ \\
\hline $\begin{array}{l}\text { 13. A preocupação que alguma coisa ruim } \\
\text { possa acontecer por causa dor é }\end{array}$ & $\begin{array}{l}\text { Mínima } \\
0\end{array}$ & $\begin{array}{c}\text { Leve } \\
1\end{array}$ & $\begin{array}{l}\text { Moderada } \\
\quad 2\end{array}$ & $\begin{array}{c}\text { Intensa } \\
\quad 3\end{array}$ & $\begin{array}{l}\text { Muito intensa } \\
\quad 4\end{array}$ \\
\hline
\end{tabular}

Magnificação ou amplificação (questões 6, 7 e 13) $=0$ a 12 pontos

Porcentagem pontuação total:

Ruminação: (questões $8-11)=0$ a 16 pontos

Porcentagem da pontuação total:

Desesperança: (questões de $1-5$ e $\overline{12)=0}$ a 24 pontos

Porcentagem da pontuação total: 
ANEXO I - Escala de Ansiedade e Depressão Hospitalar (HADS)

Este questionário foi construído para ajudar a saber como se sente. Pedimos-lhe que leia cada uma das perguntas e faça uma cruz $(\mathrm{X})$ no espaço anterior à resposta que melhor descreve a forma como se tem sentido na última semana.

Não demore muito tempo a pensar nas respostas. A sua reação imediata a cada questão será provavelmente mais correta do que uma resposta muito ponderada.

Por favor, faça apenas uma cruz $(\mathrm{X})$ em cada pergunta.

A 1) Eu me sinto tenso ou contraído:

3 ( ) A maior parte do tempo

2 ( ) Boa parte do tempo

1 ( ) De vez em quando

0 ( ) Nunca

A 3) Eu sinto uma espécie de medo, como se alguma coisa ruim fosse acontecer:

3 ( ) Sim, e de um jeito muito forte

2 ( ) Sim, mas não tão forte

1 ( ) Um pouco, mas isso não me preocupa

0 ( ) Não sinto nada disso

A 5) Estou com a cabeça cheia de preocupações:

3 ( ) A maior parte do tempo

2 ( ) Boa parte do tempo

1 ( ) De vez em quando

0 ( ) Raramente

A 7) Consigo ficar sentado à vontade e me sentir relaxado:

0 ( ) Sim, quase sempre

1 ( ) Muitas vezes

2 ( ) Poucas vezes

3 ( ) Nunca

A 9) Eu tenho uma sensação ruim de medo, como um frio na barriga ou um aperto no estômago:

0 ( ) Nunca

1 ( ) De vez em quando

2 ( ) Muitas vezes

3 ( ) Quase sempre

A 11) Eu me sinto inquieto, como se eu não pudesse ficar parado em lugar nenhum:

3 ( ) Sim, demais

2 ( ) Bastante

1 ( ) Um pouco

0 ( ) Não me sinto assim

A 13) De repente, tenho a sensação de entrar em pânico:

3 ( ) A quase todo momento

2 ( ) Várias vezes

1 ( ) De vez em quando

0 ( ) Não sinto isso

D 2) Eu ainda sinto gosto pelas mesmas coisas de antes:

0 ( ) Sim, do mesmo jeito que antes

1 ( ) Não tanto quanto antes

2 ( ) Só um pouco

3 ( ) Já não sinto mais prazer em nada

D 4) Dou risada e me divirto quando vejo coisas engraçadas:

0 ( ) Do mesmo jeito que antes

1 ( ) Atualmente um pouco menos

2 ( ) Atualmente bem menos

3 ( ) Não consigo mais

D 6) Eu me sinto alegre:

3 ( ) Nunca

2 ( ) Poucas vezes 
1 ( ) Muitas vezes

0 ( ) A maior parte do tempo

D 8) Eu estou lento para pensar e fazer as coisas:

3 ( ) Quase sempre

2 ( ) Muitas vezes

1 ( ) De vez em quando

0 ( ) Nunca

D 10) Eu perdi o interesse em cuidar da minha aparência:

3 ( ) Completamente

2 ( ) Não estou mais me cuidando como deveria

1 ( ) Talvez não tanto quanto antes

0 ( ) Me cuido do mesmo jeito que antes

$D$ 12) Fico esperando animado as coisas boas que estão por vir:

0 ( ) Do mesmo jeito que antes

1 ( ) Um pouco menos do que antes

2 ( ) Bem menos do que antes

3 ( ) Quase nunca

D 14) Consigo sentir prazer quando assisto a um bom programa de televisão, de rádio ou quando leio alguma coisa:

0 ( ) Quase sempre

1 ( ) Várias vezes

2 ( ) Poucas vezes

3 () Quase nunca

Pontuação:

\begin{tabular}{|l|c|}
\hline HADS & (Max 21) \\
\hline Ansiedade & \\
\hline Depressão & \\
\hline
\end{tabular}

